ANSP-M- 6

SEPT 1973

Copy 1 No... 52

Aerospace Nuclear Safety Program

\title{
USERS MANUAL FOR THE 3DOF TRAJECTORY COMPUTER PROGRAM
}

by L. L. PERINI

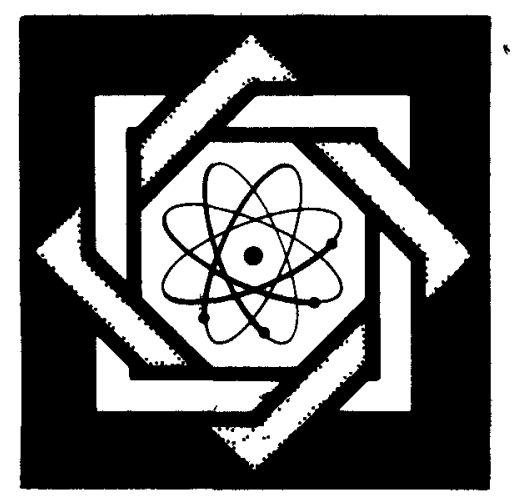

THE JOHNS HOPKINS UNIVERSITY • APPLIED PHYSICS LABORATORY

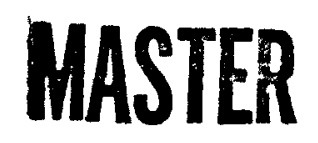




\section{DISCLAIMER}

This report was prepared as an account of work sponsored by an agency of the United States Government. Neither the United States Government nor any agency Thereof, nor any of their employees, makes any warranty, express or implied, or assumes any legal liability or responsibility for the accuracy, completeness, or usefulness of any information, apparatus, product, or process disclosed, or represents that its use would not infringe privately owned rights. Reference herein to any specific commercial product, process, or service by trade name, trademark, manufacturer, or otherwise does not necessarily constitute or imply its endorsement, recommendation, or favoring by the United States Government or any agency thereof. The views and opinions of authors expressed herein do not necessarily state or reflect those of the United States Government or any agency thereof. 


\section{DISCLAIMER}

Portions of this document may be illegible in electronic image products. Images are produced from the best available original document. 
ANSP-M-6

SEPT 1973
Aerospace Nuclear Safety Program

\section{USERS MANUAL FOR THE 3DOF TRAJECTORY COMPUTER PROGRAM}

\author{
by L. L. PERINI
}

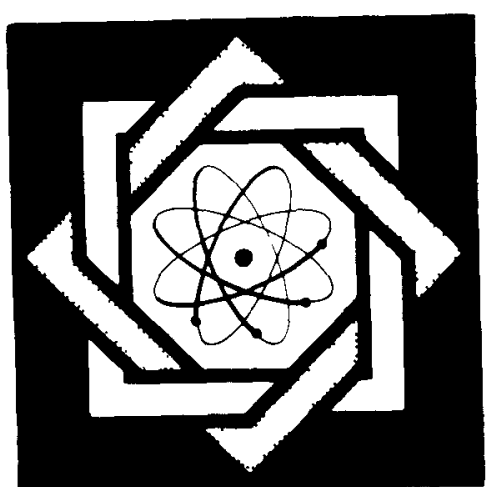

THE JOHNS HOPKINS UNIVERSITY • APPLIED PHYSICS LABORATORY 8621 Georgia Avenue 。 Silver Spring, Maryland 。 20910 
The work reported herein was conducted by the Aeronautics Division of the Applied Physics Laboratory for the Atomic Energy Commission Safety Branch, Space Nuclear Systems Office. Activities of the Aeronautics Division are under the general supervision of Dr. William H.Avery. The Project Engineer for the Aerospace Nuclear Safety Program is James C。Hagan。 
This report documents the three-degree of freedom (3DOF) reentry trajectory computer code employed in the Atomic Energy Commission Aerospace Nuclear Safety Program at the Applied Physics Laboratory. The code is written in Fortran and is operational on the IBM 360/91. A sample input deck setup is illustrated。 
THE JOHNS HOPKINS UNIVERSITY APPLIED PHYSICS LABORATORY SILVER SPRING MARYLAND

SUMMARY

The three degree of freedom Fortran computer code employed in the Atomic Energy Commission Aerospace Nuclear Safety Program at the Applied Physics Laboratory is documented herein. The basic trajectory equations are derived and the basic environmental parameters necessary for further detailed thermal studies are defined. The capability of calculat. ing skip type trajectories is included as an option.

The input variables are described and a sample input deck is shown. The computer code is relatively small and efficient, resulting in low computer costs. The program has been in use at APL for over a year and the results have been compared to other calculations performed at othes organizations with excellent agreement. The code is operational on the IBM $360 / 91$ and is a modification of a program developed by the Lockheed Missile and Space Corporation. 


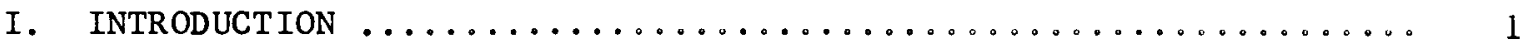

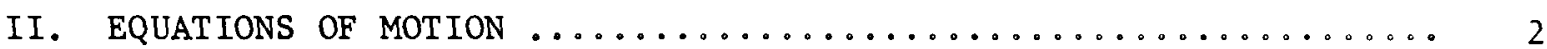

III. ENV IRONMENTAL PARAMETERS $\ldots \ldots \ldots \ldots \ldots \ldots \ldots \ldots \ldots \ldots \ldots \ldots \ldots$

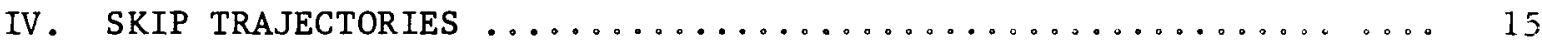

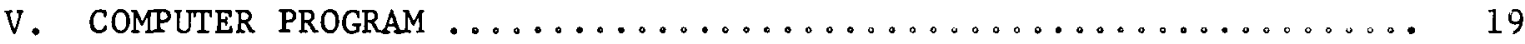

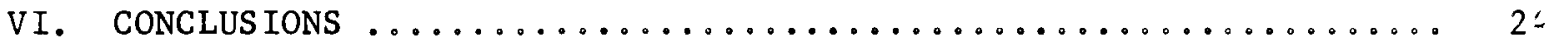

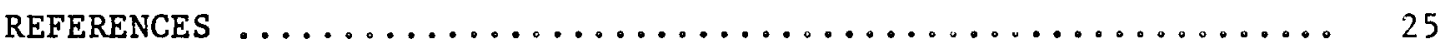

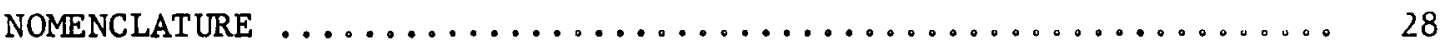

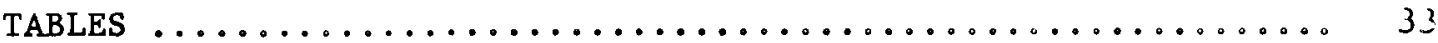

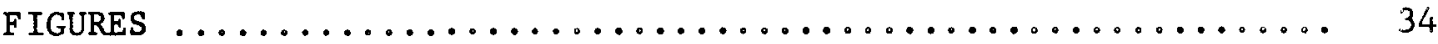

APPENDIX I. LISTING OF 3DOF COMPUTER CODE $\ldots \ldots \ldots \ldots \ldots \ldots \ldots$ A1

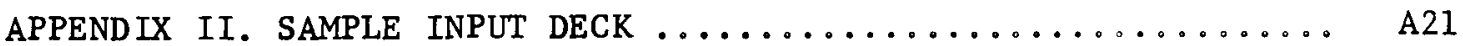


THE JOHNS HOPKINS UNIVERSITY APPLIED PHYSICS LABORATORY

SILVER SPRING MARYLAND

\section{LIST OF FIGURES}

\section{Fig. $1 \quad$ Coordinate System}

Fig. 2 Aerodynamic Force Components

Fig. 3 Relationship Between Geocentric $(\lambda, h)$ and Geodetic

$\left(\lambda_{g}, h_{g}\right)$ Latitude and A1titude 
THE JOHNS HOPKINS UNIVERSITY APPLIED PHYSICS LABORATORY Silver spring Maryland

\section{LIST OF TABLES}

Table I Stagnation Point Radiation Flux Heating Rates, Btu/ $\left(\mathrm{ft}^{2}-\mathrm{sec}\right)$ 


\section{I。 INTRODUCTION}

This report documents the modifications and additions made to the three-degree of freedom (3DOF) reentry trajectory computer code for the Atomic Energy Commission (AEC) Aerospace Nuclear Safety program. The 3DOF code was originally received by the Applied Physics Laboratory (APL) Irom Lockheed Missiles and Space Company. 1 The code was modified for use on the IBM $360 / 91$ and two versions developed, ${ }^{2}$ RAV3D and WEA3D, in conjunction with projects at APL. The development of this third version entitled 3DOF has resulted in major modifications, additions and deletions in order to satisfy the computational-requirements of the $\mathrm{AEC}$ Aerospace Nuclear Safety program.

The 1962 atmospheric model was changed from a tabular to a hydrostatic model employing lapse rates. A subroutine previously developed was utilized. In order to correctly simulate low angle-orbital speed reentries it was necessary to add an elliptical earth model and the corresponding gravity potential and to employ double precision arithmetic. In the process of completing these latter modifications, errors were found in the basic equations of motion. The input and output formats were extensively changed. Calculations of stagnation point convective and radiative heating rates to a one-foot spherical body were added along with computations of the total pressure. These latter parameters are punched on cards and utilized as inputs to the one dimensional ablation program (CMA) ${ }^{3}$ and the multidimensional Standard Heat Transfer Program (SHTP) ${ }^{4}$ for further detailed thermal studies. 
The capability of calculating 'skip' type reentries was incorporated by assuming the Keplerian equations of motion (i.e., no drag) are applicable above an input value of altitude.

A parameter indicating the stagnation point recession rate for a graphitic body is evaluated and is based on the assumption of a diffusion limited boundary layer analysis.

\section{EQUATIONS OF MOTION}

In this section are presented the equations used in the computer code for the trajectory and heating variables.

The geocentric spherical rotating coordinate system, shown in Fig. 1, is utilized. From Fig. 1 we have,

$$
\begin{gathered}
\bar{r}=r \bar{e}_{r} \\
\omega=\left(\dot{\phi}+\omega_{e}\right) \cos \theta \bar{e}_{r}-\left(\dot{\phi}+\omega_{e}\right) \sin \theta \bar{e}_{\theta}^{*}+\dot{\theta} \bar{e}_{\emptyset}
\end{gathered}
$$

The rate of change of the unit vectors are

$$
\begin{aligned}
& \dot{\bar{e}}_{r}=\bar{w} \times \bar{e}_{r} \\
& \dot{\bar{e}}_{\theta}^{*}=\bar{w} \times \bar{e}_{\theta} * \\
& \dot{\bar{e}}_{\emptyset}=\bar{\omega} \times \bar{e}_{\emptyset}
\end{aligned}
$$

The velocity and acceleration vectors are 


$$
\bar{v}=\dot{\bar{r}}=\dot{r} \bar{e}_{r}+r \dot{\theta} \bar{e}_{\theta} *+r\left(\dot{\emptyset}+\omega_{e}\right) \sin \theta \bar{e}_{\emptyset}
$$

and

$$
\overline{\mathrm{a}}=\dot{\overline{\mathrm{v}}}=\dot{\mathrm{v}}_{\mathrm{r}}^{\prime} \overline{\mathrm{e}}_{\mathrm{r}}+\mathrm{v}_{\mathrm{r}}^{\prime} \dot{\overline{\mathrm{e}}}_{\mathrm{r}}+\dot{\mathrm{v}}_{\theta}^{\prime} \overline{\mathrm{e}}_{\theta} *+\mathrm{v}_{\theta}^{\prime} \dot{\overline{\mathrm{e}}}_{\theta}^{*}+\dot{\mathrm{v}}_{\emptyset}^{\prime} \overline{\mathrm{e}}_{\emptyset}+\mathrm{v}_{\emptyset} \dot{\mathrm{e}}_{\emptyset}
$$

where

$$
\begin{aligned}
& v_{r}^{\prime}=\dot{r} \\
& v_{\theta}^{\prime}=r \dot{\theta} \\
& v_{\emptyset}^{\prime}=r\left(\dot{\emptyset}+w_{e}\right) \sin \theta
\end{aligned}
$$

The equations of motion utilized in the 3DOF program are based on a slightly modified version of the above coordinate system in that the positive direction of $\vec{e}_{\theta}$ is reversed to that utilized above (shown dotted in Fig. 1). The resulting inertial velocity and acceleration components are,

$$
\begin{gathered}
\mathrm{v}_{r}^{\prime}=\dot{\mathrm{r}} \\
\mathrm{v}_{\theta}^{\prime}=-\dot{r} \dot{v_{\emptyset}}=\mathrm{r}\left(\dot{\emptyset}+\omega_{\mathrm{e}}\right) \sin \theta \\
\mathrm{v}_{\mathrm{r}}^{\prime}=\dot{\mathrm{v}}_{\mathrm{r}}^{\prime}-\left(\mathrm{v}_{\theta}^{\prime}\right)^{2} / \mathrm{r}-\left(\mathrm{v}_{\emptyset}^{\prime}\right)^{2} / \mathrm{r} \\
\mathrm{a}_{\theta}=\dot{\mathrm{v}}_{Q}^{\prime}+\mathrm{v}_{r}^{\prime} \mathrm{v}_{\theta}^{\prime} / \mathrm{r}+\left(\mathrm{v}_{\emptyset}^{\prime}\right)^{2} /(\mathrm{r} \tan \theta) \\
\mathrm{a}_{\emptyset}=\dot{\mathrm{v}}_{\emptyset}^{\prime}+\mathrm{v}_{\mathrm{r}}^{\prime} \mathrm{v}_{\emptyset}^{\prime} / \mathrm{r}-\mathrm{v}_{\emptyset}^{\prime} \mathrm{v}_{\theta}^{\prime} /(\mathrm{r} \tan \theta)
\end{gathered}
$$

Converting from inertial to relative coordinates 
THE JOHNS HOPKINS UNIVERSITY

APPLIED PHYSICS LABORATORY

Silver SPRING MARYLAND

$$
v_{\emptyset}=v_{\emptyset}^{\prime}-r \omega_{e} \sin \theta
$$

and utilizing Newton's law $\overline{\mathrm{F}}=\mathrm{m} \cdot \overline{\mathrm{a}}$ we then have

$$
\left.\begin{array}{l}
\mathrm{v}_{\mathrm{r}}=\dot{\mathrm{r}} \\
\mathrm{v}_{\theta}=-\mathrm{r} \dot{\theta} \\
\mathrm{v}_{\emptyset}=\mathrm{r} \dot{\emptyset} \sin \theta \\
\dot{\mathrm{v}}_{\mathrm{r}}=\mathrm{F}_{\mathrm{r}} / \mathrm{m}+\mathrm{v}_{\theta}^{2} / \mathrm{r}+\mathrm{v}_{\emptyset}^{2} / \mathrm{r}+2 \mathrm{v}_{\emptyset} \omega_{\mathrm{e}} \sin \theta-\mathrm{r} \omega_{e}^{2} \sin ^{2} \theta \\
\dot{\mathrm{v}}_{\theta}=\mathrm{F}_{\theta} / \mathrm{m}-\mathrm{v}_{\mathrm{r}} \mathrm{v}_{\theta} / \mathrm{r}-\mathrm{v}_{\emptyset}{ }^{2} /(\mathrm{r} \tan \theta)-2 \mathrm{v}_{\emptyset} \omega_{e} \cos \theta-\mathrm{r} \omega_{e}{ }^{2} \sin \theta \cos \theta \\
\dot{\mathrm{v}}_{\emptyset}=\mathrm{F}_{\emptyset} / \mathrm{m}-\mathrm{v}_{\mathrm{r}} \mathrm{v}_{\emptyset} / \mathrm{r}+\mathrm{v}_{\theta} \mathrm{v}_{\emptyset} /(\mathrm{r} \tan \theta)-2 \omega_{\mathrm{e}}\left(\mathrm{v}_{\mathrm{r}} \sin \theta-\mathrm{v}_{\theta} \cos \theta\right)
\end{array}\right\} \quad(10)
$$

The total relative velocity is given by

$$
v=\left(v_{r}^{2}+v_{\emptyset}^{2}+v_{\theta}^{2}\right)^{1 / 2}
$$

The initial conditions are specified by $t_{0}, \gamma_{0}, A_{0}, \lambda_{0}, L_{0}, h_{0}$ and $V_{0}$ from which we have

$$
\begin{aligned}
& \theta_{0}=90-\lambda_{0} \\
& \emptyset_{0}=L_{0} \\
& r_{0}=h_{0}+R_{e} \\
& \left(v_{r_{0}}\right)_{0}=v_{0} \sin \gamma_{0} \\
& \left(v_{\theta}\right)_{0}=v_{0} \cos \gamma_{0} \cos A_{0} \\
& \left(v_{\emptyset}\right)_{0}=v_{0} \cos \gamma_{0} \sin A_{0}
\end{aligned}
$$

$-4-$ 
The initial conditions can be input in either relative or inertial coordi* nates. If the inputs are in inertial coordinates the relative values are computed from $^{5}$

$$
\begin{aligned}
& V=V^{\prime}\left[1+C^{2}-2 C \cos \gamma^{\prime} \sin A^{\prime}\right]^{1 / 2} \\
& Y=\sin ^{-1}\left(V^{\prime} \sin \gamma^{\prime} / V\right) \\
& A=\tan ^{-1}\left[\left(\sin A^{\prime}-C / \cos \gamma^{\prime}\right) / \cos A^{\prime}\right]
\end{aligned}
$$

where

$$
c=r \omega_{e} \cos \lambda / v^{\prime}
$$

The flight path angle and azimuth are given by

$$
\begin{aligned}
& \gamma=\tan ^{-1}\left(v_{r} / \sqrt{v_{\theta}^{2}+v_{\emptyset}^{2}}\right) \\
& A=\tan ^{-1}\left(v_{\emptyset} / v_{\theta}\right)
\end{aligned}
$$

The force components $\bar{F}$ consist of two sets of forces, aerodynamic forces $\overline{\mathrm{F}}_{\mathrm{A}}$ and gravity forces $\overline{\mathrm{F}}_{\mathrm{g}}$. The aerodynamic forces are specified by values of $C_{D}, C_{L} / C_{D}$ (drag and lift are axial and normal, respectively, to the velocity vector) and $C_{Y} / C_{D}$ (represents a yaw force normal to the $L-D$ plane). A number of options are available in specifying $C_{D}$. Tabular values as a function of either $h$ or $M_{\infty}$ can be input and these will be defined in Section $V_{0}$ An analytic relation for $C_{D}$ can also be selected based on a simi-empirical method of Matting ${ }^{6}$ that provides a definition of $C_{D}$ from the free molecular flow regime to the continuum flow regime, 


$$
C_{D}=c_{D_{C}}\left\{1+\left|c_{D_{F M F}}-C_{D_{C}}\right| \operatorname{EXP}\left[-7.32 \times 10^{6} \mathrm{R}_{\mathrm{GL}} \rho_{\infty}\left(1+E_{\mathrm{D}}\right)\right]\right\}
$$

where $C_{D_{C}}$ and $C_{D_{F M F}}$ are, respectively, the continuum and free molecular flow values of the drag coefficient. $R$ is the nose radius in feet and $E_{D}$ is an empirical input variable whereby the user can modify the form of the relationship based on experimental data as discussed in Ref。6. The lift/ drag and yaw/drag ratios are input constants. The drag, lift and yaw forces are then given by

$$
\begin{aligned}
& A_{D}=C_{D} q_{\infty} A_{r e f} \\
& A_{L}=A_{D}\left(C_{L} / C_{D}\right) \\
& A_{Y}=A_{D}\left(C_{Y} / C_{D}\right)
\end{aligned}
$$

The three aerodynamic force components are then

$$
\overline{\mathrm{F}}_{A}=\mathrm{F}_{A r} \overline{\mathrm{e}}_{r}+\mathrm{F}_{A \theta} \overline{\mathrm{e}}_{\theta}+\mathrm{F}_{A \emptyset} \overline{\mathrm{e}}_{\emptyset}
$$

where, referring to Fig. 2

$$
\begin{aligned}
& F_{A r}=-A_{D} \sin \gamma+A_{L} \cos \gamma \\
& F_{A \theta}=-A_{D} \cos \gamma \cos A-A_{L} \sin \gamma \cos A-A_{Y} \sin A \\
& F_{A \emptyset}=-A_{D} \cos \gamma \sin A-A_{L} \sin \gamma \sin A+A_{Y} \cos A
\end{aligned}
$$

Two earth models are available in the 3DOF code, a spherical or elliptical representation. For the spherical assumption gravity acts along $\bar{e}_{r}$ and is simply given by

$$
g_{r}=g_{S L}\left(R_{e} / r\right)^{2}
$$


where

$$
\begin{aligned}
& R_{e}=20.898908 \times 10^{6} \text { feet } \\
& g_{S L}=32.174 \mathrm{ft} / \mathrm{sec}^{2} \\
& r=R_{e}+h
\end{aligned}
$$

For the ellipsoidal earth model the gravity potential function in spherical harmonics ${ }^{7}$ up to the second harmonic is assumed,

$$
U(r, \lambda)=\mu / r+\epsilon \mu\left(1-3 \sin ^{2} \lambda\right) /\left(3 r^{3}\right)
$$

where we have used,

$$
\begin{aligned}
& \mu=1.40762913 \times 10^{16} \mathrm{ft}^{3} / \mathrm{sec}^{2} \\
& \epsilon=7.148788887 \times 10^{11} \mathrm{ft}^{2}
\end{aligned}
$$

The gravity components are given by

$$
m \bar{F}_{g}=-\frac{\partial U}{\partial r} \bar{e}_{r}-\frac{1}{r} \frac{\partial U}{\partial \lambda} \bar{e}_{\theta}=g_{r} \bar{e}_{r}+g_{\theta} \bar{e}_{\theta}
$$

or

$$
\begin{aligned}
& g_{r}=-\mu / r^{2}-\mu \varepsilon\left(1-3 \sin ^{2} \lambda\right) / r^{4} \\
& g_{\theta}=-2 \mu \epsilon \sin \lambda \cos \lambda / r^{4}
\end{aligned}
$$

The earth's radius is now a function of the geocentric latitude, $\lambda$,

$$
\begin{aligned}
& \mathrm{R}_{\mathrm{e}}(\lambda)=\mathrm{R}_{\mathrm{eq}} /\left(1-\mathrm{e}_{3} \sin ^{2} \lambda\right)^{1 / 2 \cdots} \\
& \mathrm{e}_{3}=1-\left(\mathrm{R}_{\mathrm{eq}} / \mathrm{R}_{\mathrm{p}}\right)^{2}
\end{aligned}
$$


where

$$
\begin{aligned}
& \mathrm{R}_{\text {eq }}=\text { equatorial radius }=20.92554 \times 10^{6} \mathrm{ft} \\
& \mathrm{R}_{\mathrm{p}}=\text { polar radius }=20.855107 \times 10^{6} \mathrm{ft}
\end{aligned}
$$

For the accurate determination of aerodynamic forces the geodetic altitude $h_{\mathrm{g}}$ is required and for range calculations values of the geodetic latitude $\lambda_{g}$ are required. A sketch of the relationship between the geodetic values and the geocentric values is shown in Fig. 3 . Based on the approximations outlined in Ref。 8 , values of $h-h_{g}$ and $\lambda-\lambda_{g}$ were evaluated as a function of $\mathrm{h}$ and $\lambda_{\text {。 }}$ Maximum deviations of $\mathrm{h}-\mathrm{h}_{\mathrm{g}} \simeq 0$ to 5 meters occurred at $\lambda=45^{\circ}$ in the region of interest, $h<500 \mathrm{~km}$ 。 The differences are sma11 and the correction was therefore not made. Similarly a maximum deviation of $\lambda-\lambda_{\mathrm{g}}=-0.19^{\circ}$ resulted at $\lambda=45^{\circ}$ and for $\mathrm{h}<500 \mathrm{~km}$. As accurate range calculations are not of primary concern for the AEC safety studies, this correction was also not incorporated.

The equations are numerically integrated by the Runge-Kutta method with a variable time step selected from

$$
\Delta t=0.01(V+2000) / \sqrt{\dot{V}_{r}^{2}+\dot{V}_{\emptyset}^{2}+\dot{V}_{\theta}^{2}}
$$

subject to maximum and minimum constraints specified by input variables。* The following integrations are performed,

*Maximum and minimum values of 1.0 and 0.1 seconds are currently employed. 


$$
\begin{aligned}
& v_{r}\left(t_{i+1}\right)=v_{r}\left(t_{i}\right)+\int_{\Delta t} \dot{v}_{r} d t \\
& v_{\theta}\left(t_{i+1}\right)=v_{\theta}\left(t_{i}\right)+\int_{\Delta t} \dot{v}_{\theta} d t \\
& v_{\emptyset}\left(t_{i+1}\right)=v_{\emptyset}\left(t_{i}\right)+\int_{\Delta t} \dot{v}_{\emptyset} d t \\
& r\left(t_{i+1}\right)=r\left(t_{i}\right)+\int_{\Delta t} \dot{r} d t \\
& \theta\left(t_{i+1}\right)=\theta\left(t_{i}\right)-\int_{\Delta t}\left(v_{\theta} / r\right) d t \\
& \emptyset\left(t_{i+1}\right)=\emptyset\left(t_{i}\right)+\int_{\Delta t} v_{\emptyset} /(r \sin \theta) d t
\end{aligned}
$$

\section{ENVIRONMENTAL PARAMETERS}

The evaluation of environmental reentry parameters for a particular trajectory is the primary output of the computer code, and described below are the correlations, equations and methods employed in the 3DOF computer code in defining the various output parameters.

Mach Number

$$
\mathrm{M}=\mathrm{V} / \mathrm{a}_{\infty}
$$

where $a_{\infty}$ is the free stream speed of sound, ft/sec, based on the 1962 standard atmosphere. 9

Tota1 Enthalpy

$$
\mathrm{h}_{\mathrm{T}_{\mathrm{S}}}=\mathrm{C}_{\mathrm{p}}\left(\mathrm{T}_{\infty}-\mathrm{T}_{\text {ref }}\right)+\mathrm{v}^{2} /\left(2 \mathrm{~g}_{\mathrm{SL}} \mathrm{J}\right), \mathrm{Btu} / \mathrm{lb}
$$

where

$$
\mathrm{C}_{\mathrm{p}}=0.24 \mathrm{Btu} /\left(1 \mathrm{~b}-{ }^{\mathrm{O}} \mathrm{R}\right), \quad \mathrm{T}_{\text {ref }}=536.69^{\circ} \mathrm{R}
$$

and $2 \mathrm{gJ}=50062.7\left(\mathrm{ft}^{2} / \mathrm{sec}^{2}\right) /(\mathrm{Btu} / \mathrm{lb})$ 。 
Reynolds Number

$$
R_{N}=\rho_{\infty} V_{\text {ref }} / \mu_{\infty}
$$

where $\mu_{\infty}$ is evaluated from Sutherland's viscosity relationship for air with $\mathrm{T}_{\infty}$ (see Eq. 44 below).

Knudsen Number

$$
\mathrm{K}_{\mathrm{N}}=\mathrm{M}_{\infty} / \sqrt{\mathrm{R}_{\mathrm{N}}}
$$

where the boundary layer thickness is employed as the characteristic dimension.

Ballistic Coefficient

$$
=W /\left(C_{D} A_{r e f}\right), \quad 1 b / f t^{2}
$$

Dynamic Pressure

$$
q_{\infty}=\rho_{\infty} v^{2} / 2, \quad 1 b / f t^{2}
$$

Range $^{*}$
$R=R_{0}+\left[\left(-D_{r} \cos A_{o}+C_{r} \sin A_{O}\right)^{2}+\left(D_{r} \sin A_{o}+C_{r} \cos A_{o}\right)^{2}\right]^{1 / 2}, N \cdot M_{0}$

where

$$
\begin{aligned}
& D_{r}=\left(\theta-\theta_{o}\right) R_{e} / 6080.0, N . M . \\
& C_{r}=\left(\emptyset-\emptyset_{0}\right) R_{e} \sin \theta_{0} / 6080.0, N_{0} M_{0}
\end{aligned}
$$

\section{Total Pressure}

The total pressure behind a normal shock, $\mathrm{P}_{\mathrm{T}_{\mathrm{S}}}$, is evaluated in the hypersonic regime $\left(\mathrm{M}_{\infty}>5\right)$ from the hypersonic approximation,

\footnotetext{
* The equation for range assumes a spherical earth and, in addition, is valid for short ranges only. It is planned to employ the appropriate representation in the near future. 


$$
\mathrm{P}_{\mathrm{T}_{\mathrm{S}}}=2 \mathrm{q}_{\infty}=\gamma_{2} \mathrm{P}_{\infty} \mathrm{M}_{\infty}^{2} / 2116.224 \text {, atm }
$$

Comparison to equilibrium normal shock solutions ${ }^{10}$ has resulted in a value of $Y_{2}=1.35$ as yielding the best results. In the supersonic regime $(1<$ $\left.M_{\infty} \leq 5\right)$ the perfect gas Mach functions ${ }^{11}$ are employed

$$
P_{T_{S}}=\frac{P_{\infty}}{2116.224}\left(\frac{Y_{1}+1}{2} M_{\infty}^{2}\right)^{\frac{Y_{1}}{Y_{1}-1}}\left(\frac{Y_{1}+1}{2 \gamma_{1} M_{\infty}^{2}-Y_{1}+1}\right)^{\frac{1}{\gamma_{1}-1}} \text {, atm }
$$

where $\gamma_{1}$ is a mean value based on empirical curve fits to the NBS ${ }^{12}$ air tables,

$$
\gamma_{1}=(1.4+\gamma) / 2
$$

where

$$
\begin{aligned}
& Y=1.4 \text { for } \mathrm{T}_{\mathrm{T}_{\mathrm{S}}} \leq 500^{\circ} \mathrm{R} \\
& Y=\frac{3.3+\mathrm{T}_{\mathrm{T}_{\mathrm{S}}} / 2750}{2.3+\mathrm{T}_{\mathrm{T}_{\mathrm{S}}} / 2750} \text { for } 550<\mathrm{T}_{\mathrm{T}_{\mathrm{S}}}<3300^{\circ} \mathrm{R} \\
& \gamma=1.286 \text { for } \mathrm{T}_{\mathrm{T}_{\mathrm{S}}}>3300^{\circ} \mathrm{R} \\
& \mathrm{T}_{\mathrm{T}_{\mathrm{S}}}=\mathrm{T}_{\infty}\left(1+\frac{\gamma_{1}-1}{2} \mathrm{M}_{\infty}^{2}\right),{ }_{\mathrm{R}}
\end{aligned}
$$

In the subsonic regime $\left(M_{\infty} \leq 1\right)$,

$$
\mathrm{P}_{\mathrm{T}_{\mathrm{S}}}=\frac{\mathrm{P}_{\infty}}{2116.224}\left(1+\frac{\gamma-1}{2} \mathrm{M}_{\infty}^{2}\right)^{\frac{\gamma}{\gamma-1}} \text {, atm }
$$

where $\gamma=1.4$ 。 

lized $^{13}$ for the stagnation point, one-foot sphere value. The correlation, for a cold wa11, is given by

$$
\dot{q}_{c}=\frac{17600}{\sqrt{R}}\left(\frac{\rho_{\infty}}{\rho_{S L}}\right)^{1 / 2}\left(\frac{\mathrm{V}}{\widetilde{V}_{s}}\right)^{3.15}, B t u /\left(\mathrm{ft}^{2}-\mathrm{sec}\right)
$$

where $\rho_{\mathrm{SL}}$ is the sea level density $\left(2.3768 \times 10^{-3} 1 \mathrm{~b}-\mathrm{sec}^{2} / \mathrm{ft} t^{4}\right)$ and $\widetilde{v}_{\mathrm{s}}$ is a reference speed, satellite speed $(26000 \mathrm{ft} / \mathrm{sec})$ 。

Subsonic-Supersonic $\left(M_{\infty} \leq 6\right)$ Laminar Convective Heating Rate

Below $M_{\infty}=6$ the stagnation point, one foot sphere value is determined from the Sibulkin ${ }^{14}$ relationship represented by *

$$
\stackrel{\circ}{\mathrm{q}}_{\mathrm{C}}=\frac{0.945}{\sqrt{\mathrm{R}}} \mathrm{h}_{\mathrm{T}_{\mathrm{S}}}\left(\rho_{\mathrm{s}} \mu_{\mathrm{s}}{ }_{\mathrm{s}} \mathrm{V} / 2\right)^{1 / 2}, \mathrm{Btu} /\left(\mathrm{ft}^{2}-\mathrm{sec}\right)
$$

where $\rho_{\mathrm{S}}$ is the density behind a normal shock evaluated from the RankineHugoniot relations,

$$
\begin{aligned}
& P_{2}=2 P_{\infty}\left(\gamma M_{\infty}^{2}-\frac{\gamma-1}{2}\right) /(\gamma+1), \quad I b / f t^{2} \\
& M_{2}=\left[\frac{1+(\gamma-1) M_{\infty}^{2} / 2}{\gamma M_{\infty}^{2}-(\gamma-1) / 2}\right]^{1 / 2}
\end{aligned}
$$

\footnotetext{
${ }^{*}$ The stagnation temperatures below $M_{\infty}=6$ are relatively low $\left(<5000^{\circ} \mathrm{R}\right)$ and dissociation is small. Air is therefore treated as a calorically perfect gas.
} 


$$
\begin{aligned}
& \mathrm{T}_{\mathrm{s}}=\mathrm{T}_{\infty}\left[1+(\gamma-1) \mathrm{M}_{\infty}^{2} / 2\right],{ }^{\mathrm{o}_{\mathrm{R}}} \\
& \mathrm{P}_{\mathrm{s}}=\mathrm{P}_{2}\left[1+(\gamma-1) \mathrm{M}_{2}^{2} / 2\right]^{\frac{\gamma}{\gamma-1}}, 1 \mathrm{~b} / \mathrm{ft}^{2} \\
& \rho_{S}=\mathrm{P}_{\mathrm{s}} /\left(\mathrm{R}_{\mathrm{g}} \mathrm{T}_{\mathrm{s}} \mathrm{g}_{\mathrm{SL}}\right), 1 \mathrm{~b}-\mathrm{sec}^{2} / \mathrm{ft}^{4}
\end{aligned}
$$

where $R_{g}=53.3(\mathrm{ft}-1 \mathrm{~b}) /\left(1 \mathrm{~b}={ }^{\circ} \mathrm{R}\right)$. A value of $\gamma=1.2$ is employed in order to provide a smooth transition to the hypersonic correlation, Eq. 41, at $\mathrm{M}_{\infty}=6$. In the subsonic and low supersonic range Eq. 41 is relatively insensitive to the value of $\varphi_{0}$ The viscosity $\mu_{\mathrm{s}}$ is evaluated from the Sutherland ${ }^{12}$ relation

$$
\mu_{\mathrm{s}}=9.898 \times 10^{-7}\left(\frac{\mathrm{T}_{\mathrm{s}}}{1.8}\right)^{3 / 2} /\left(110.4+\mathrm{T}_{\mathrm{s}} / 1.8\right), 1 \mathrm{~b} /(\text { ft-sec })
$$

with $\mathrm{T}_{\mathrm{S}}$ in ${ }^{\mathrm{O}} \mathrm{R}$. Below $\mathrm{M}_{\infty}=1 \mathrm{Eq} \cdot 43$ is used to evaluate $\mathrm{P}_{\mathrm{S}}$ with $\mathrm{P}_{2}=\mathrm{P}_{\infty}$ and $M_{2}=M_{\infty}$. The stagnation point velocity gradient $\beta_{s}$ below $M_{\infty}=4.98$ is given by,

$$
\begin{aligned}
\beta_{S} & =\frac{D}{V}\left(\frac{d U_{e}}{d x}\right)_{S=0}=2.74041-0.7121196 M_{\infty} \\
& =0.125607 M_{\infty}^{2}+0.0978086 M_{\infty}^{3}=0.01148119 M_{\infty}^{4}
\end{aligned}
$$

and represents a least squares fit to experimental data ${ }^{15}$ based on a perfect gas test of a spherical body. Above $M_{\infty}=4.98$ the hypersonic modified Newtonian value for a sphere of $\beta_{s}=1.1$ is utilized. 
Free Molecular Flow Stagnation Point Heating Rate

In the free molecular flow regime the convective stagnation point heating rate is represented by

$$
\dot{\mathrm{q}}_{\mathrm{FMF}}=\rho_{\infty} \mathrm{V}^{3} /(2 \mathrm{~J}), \mathrm{Btu} /\left(\mathrm{ft} \mathrm{t}^{2}-\mathrm{sec}\right)
$$

where a unit accommodation coefficient has been assumed.

Stagnation Point Radiative Heat Transfer

For the radiative heat flux, theoretical calculations based on a computer code developed by $\mathrm{Ca} 11$ is $^{16}$ are utilized based on $\mathrm{R}=1$ foot. The results are based on inviscid, equilibrium stagnation point shock layer with non-gray emission and absorption of radiation. An eight step absorption model for air developed by 01 stad $^{17}$ is employed. Two of the steps in the eight step model have been modified at APL based on comparisons to more exact calculations from NASA Langley. 18

Tabular values of $\stackrel{\circ}{q}_{\text {rad }}$ as a function of $V$ and $h$ are incorporated in the 3DOF computer code and shown in Table I. Logarithmic inter. polation is employed for values not listed in Table I.

\section{Diffusion Limited Recession Rate}

As an indicator of total recession, the recession of a graphitic material in the diffusion limited regime is evaluated throughout the tra* jectory. For carbon-air the mass loss rate is given by ${ }^{19}$

$$
\dot{\mathrm{m}}_{\mathrm{D}}=0.1725\left(\rho_{e} \mathrm{U}_{\mathrm{h}} \mathrm{C}_{\mathrm{h}}\right),\left(1 \mathrm{~b} / \mathrm{ft} \mathrm{t}^{2}-\mathrm{sec}\right)
$$


where

$$
\rho_{e} \mathrm{U}_{\mathrm{e}} \mathrm{C}_{\mathrm{h}}=\dot{q} / \mathrm{h}_{\mathrm{T}_{\mathrm{s}}}, \mathrm{lb} /\left(\mathrm{ft} \mathrm{t}^{2}-\mathrm{sec}\right)
$$

and $\dot{q}$ is evaluated from Matting's bridging relationship between the continuum and free molecular flow regimes, 6

$$
\dot{q}=f \dot{q}_{c}\left(1-e^{\frac{\dot{q}_{F M F}}{\dot{f}_{\mathrm{q}}}}\right), B t u /\left(f t^{2}-\mathrm{sec}\right)
$$

and $f$ is an input parameter used to modify the one foot spherical heating rate to a different geometry and/or nose radii and to account for blowing effects. The total mass loss is then

$$
W_{D}=\int \dot{m}_{D} d t, 1 b / f t^{2}
$$

and the recession is given by

$$
\mathrm{S}=12 \mathrm{w}_{\mathrm{D}} / \rho_{\text {grap }} \text {, inches }
$$

It should be noted that the above analysis will, in general, result in a lower bound to a more realistic analysis incorporating effects of sublimation and erosion for steep reentries. In the case of skip type trajectories, to be discussed in Section IV, the above analysis will result in higher mass loss rates than a more realistic analysis.

\section{SKIP TRAJECTORIES}

One of the design trajectories for the safety studies is a multiple skip reentry. The skip trajectories result when the velocity 
THE JOHNS HOPKINS UNIVERSITY APPLIED PHYSICS LABORATORY

SILVER SPRING MARYLAND

is sufficiently high, greater than satellite circular speed, and the flight path angle sufficiently small, such that the body is not captured on a reentry from $400 \mathrm{Kft}$ (or some other specified arbitrary h) but rather escapes temporarily on a Kepler orbit and returns later for a subsequent reentry. On each skip energy is dissipated during the atmospheric portion of flight (near perigee) and the body will eventually be captured. The capability of calculating skip trajectories in an approximate manner has been incorporated in the program. The major assumption employed is that the atmosptere is assumed to be negligible above a prespecified height and that the drag-free vacuum Keplerian equations are valid resulting in the use of simplified algebraic relations for the orbital equations of motion. This procedure provides a great reduction in computer costs and for thermal studies is sufficiently accurate. In essence the reentry conditions $\left(h_{0}, v_{0}, \gamma_{0}\right)$ for each skip is equivalent to the exit conditions for the previous skip (he, $\left.V_{e}, \gamma_{e}\right)$ except that the sign of $\gamma$ is reversed $\left(\gamma_{0}=-\gamma_{e}\right)$. The calculations incorporated in the program are directed toward evaluating the orbital parameters and in calculating latitude, longitude and azimuth. The majority of the equations employed are taken from Ref. 20. The eccentricity e cf the orbit is evaluated from the inertial atmospheric exit condition $V_{e}^{\prime}{ }^{\prime}{ }_{e}$ and $Y_{e}^{\prime}$

$$
e=\left[1+\left(\nu_{e}^{2}-2\right) \nu_{e}^{2} \cos ^{2} \psi_{e}^{\prime}\right]^{1 / 2}
$$

where

$$
\begin{aligned}
& v_{e}=v_{e}^{\prime} / v_{s} \\
& v_{s}=\sqrt{g_{r} r_{e}} \frac{R_{e}}{r_{e}}
\end{aligned}
$$


The orbit perigee and apogee are then

$$
\begin{aligned}
& r_{p}=r_{e} \nu_{e}^{2} \cos ^{2} \gamma_{e}^{\prime} /(1+e) \\
& r_{a}=r_{e} \nu_{e}^{2} \cos ^{2} \gamma_{e}^{\prime} /(1-e)
\end{aligned}
$$

The anomaly $\Psi_{\mathrm{e}}$ is found from $(\Psi=0$ at perigee $)$

$$
\Psi_{e}=\cos ^{-1}\left[\left(\nu_{e}^{2} \cos ^{2} \gamma_{e}^{\prime}-1\right) / e\right]
$$

where the semi-major axis is,

$$
a=\left(r_{p}+r_{a}\right) / 2
$$

The anomaly at reentry is

$$
\Psi_{0}=360-\Psi_{e}
$$

The flight time from $\Psi=0$ is

$$
t(\Psi)=\frac{a^{3 / 2}}{\sqrt{g_{S L}} R}\left[2 \tan ^{-1}\left(\sqrt{\frac{1-e}{1+e}} \tan \frac{\Psi}{2}\right)-\frac{e \sqrt{1-e^{2}} \sin \Psi}{1+e \cos \Psi}\right]
$$

so that the flight time from $\Psi_{e}$ to $\Psi_{0}$ is

$$
\Delta t=t_{e}\left(\Psi_{e}\right)-t_{0}\left(\Psi_{0}\right)
$$

The time for a complete revolution is given by Eq. 60 with $\psi=360^{\circ}$ and

$$
t=2 \pi a^{3 / 2} /\left(\sqrt{g_{S L}} R\right)
$$


THE JOHNS HOPKINS UNIVERSITY APPLIED PHYSICS LABORATORY

SILVER SPRING MARYLAND

The inclination of the orbit plane to the equator can be found from the inertial azimuth $\mathrm{A}_{\mathrm{e}}^{\prime}$ and the inertial geocentric latitude $\lambda_{\mathrm{e}}^{\prime}$

$$
i=\cos ^{-1}\left(\cos \lambda_{e}^{\prime} \sin A_{e}^{\prime}\right)
$$

The reentry latitude is given by

$$
\lambda_{0}=\sin ^{-1}\left(\sin \widetilde{\Psi}_{0} \sin i\right)
$$

where $\widetilde{\Psi}_{0}$ is the reentry central angle measured from the line of nodes (i.e., the intersection of the orbit plane and the equator)

$$
\begin{aligned}
& \widetilde{\Psi}_{0}=\Psi_{0}-\Psi_{e}+\widetilde{\psi}_{e} \\
& \Psi_{e}=\sin ^{-1}\left(\sin \lambda_{e}^{\prime} / \sin i\right)
\end{aligned}
$$

The reentry inertial azimuth is given by

$$
A_{0}^{\prime}=\sin ^{-1}\left(\cos i / \cos \lambda_{0}^{\prime}\right)
$$

The reentry longitude measured from the line of modes is

$$
\tilde{\mathrm{I}}_{0}=\sin ^{-1}\left(\cos \lambda_{0} \sin A_{0}\right)
$$

and the initial inertial true longitude is

$$
L_{0}^{\prime}=\tilde{L}_{o}+L_{e}^{\prime}-\omega_{e}\left(t_{e}-t_{0}\right)
$$




\section{COMPUTER PROGRAM}

The program is written in Fortran and is operational on the IBM $360 / 91$. A 1isting of the source code is tabulated in Appendix I. Six subroutines are employed by the main program:

\begin{tabular}{|c|c|}
\hline ATM & The 1962 standard atmosphere 21 \\
\hline AZMUTH & $\begin{array}{l}\text { A function subroutine that determines the azimuth, } \\
\text { A, from the velocity components }\end{array}$ \\
\hline CALC & $\begin{array}{l}\text { Performs calculations and table look-ups to evalu- } \\
\text { ate the aerodynamic forces }\end{array}$ \\
\hline KEPLER & $\begin{array}{l}\text { Used during skip trajectories. Orbit parameters } \\
\text { are evaluated and reentry conditions are evaluated }\end{array}$ \\
\hline$\emptyset \mathrm{UTPT}$ & Prints the output at the specified time point \\
\hline PIF 1 & $\begin{array}{l}\text { A function subroutine that performs linear inter- } \\
\text { polation }\end{array}$ \\
\hline
\end{tabular}

Shown in Appendix II is a sample program setup along with the job control cards required to execute the program that currently resides on a 'BHP' 1ibrary at the Applied Physics Laboratory. * A number of options with respect to program control are available to the user through input parameters. A description of the input variables and their formats follow.

The first card in the input deck is a title card that is printed at the top of each page of output. Information describing and/or identifying the run is punched on this card in columns 1 to 68 . The title card is followed by a block of 'namelist' data called INPUT. The signal to the program that this data follows is \&INPUT punched anywhere on the next card

\footnotetext{
* Contact the author as to the current library indexes in the event the program is desired to be used.
} 
THE JOHNS HOPKINS UNIVERSITY APPLIED PHYSICS LABORATORY SILVER SPRING MARYLAND

following the title card. The following variables are included in the data block.

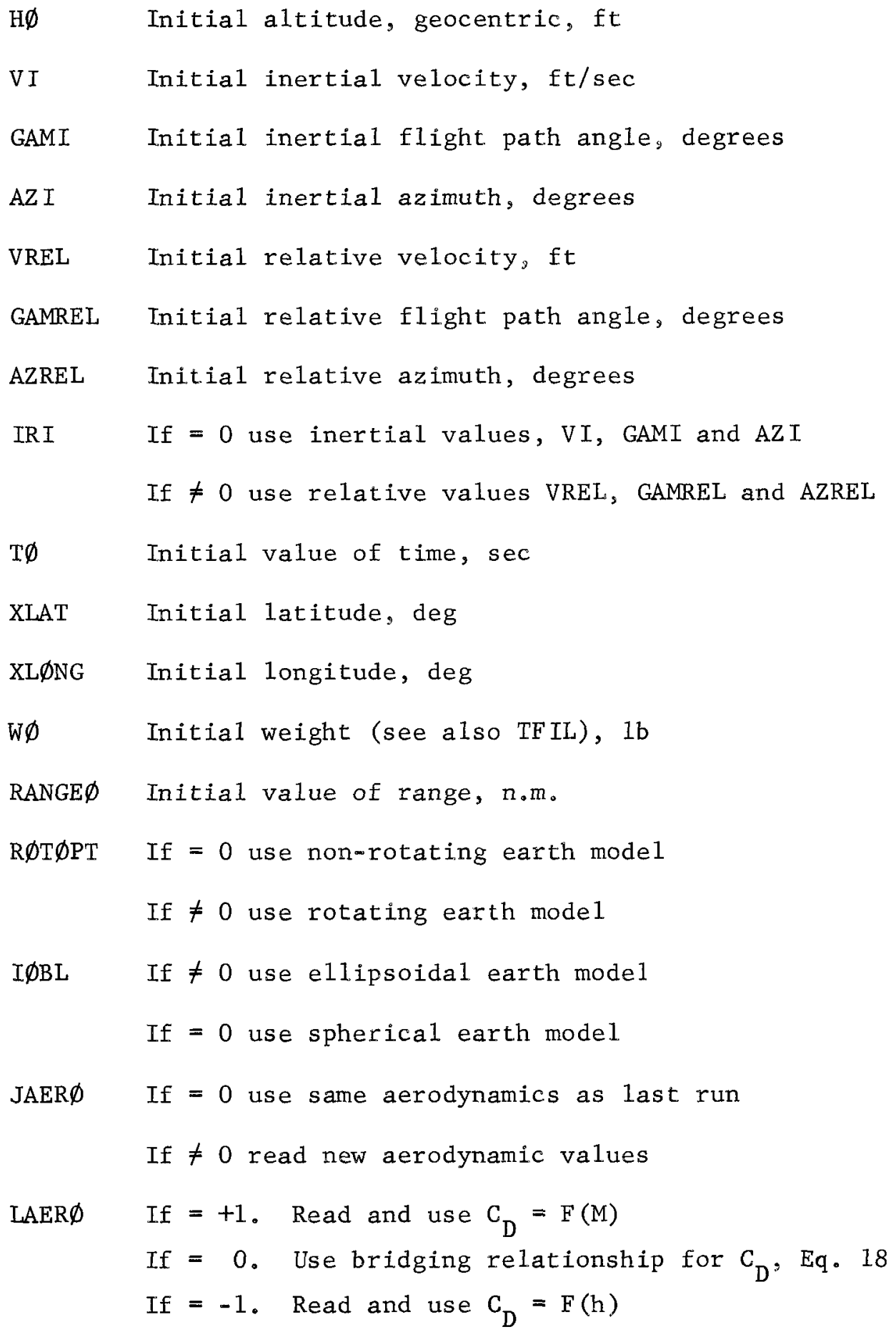



ship, Eq. 18

CDFM Free molecular flow drag coefficient used in bridging relationship, Eq. 18

RNøSE Nose radius, ft, used in bridging relationship, Eq. 18

ED Empirical constant used to modify bridging relationship, Eq. 18, equal to 0 for a sphere

SKINFR If $>0.0$ read and print skin friction coefficient $\mathrm{C}_{\mathrm{f}}=$ $f(h, v)$ table. The skin friction coefficient is added to $\mathrm{C}_{\mathrm{D}}$

DWT If $>0.0$ read and print weight loss $=f(h)$ table

TFIL If $>0.0$ use WFIL and CAFIL values listed below for weight. and $\mathrm{C}_{\mathrm{A}}$ factors

WFIL Vehicle weight if $t<T F I L 。 W_{0}$ used for vehicle weight when $\mathrm{t}>\mathrm{TFIL}$

CAFIL Multiplying factor for $C_{D}$ if $t<T F I L$

SWMCH If $>0.0$ read $C_{D}=f(M)$ table and use when $M<$ SWMCH

SWALT If $>0.0$ read $C_{D}=f(M)$ table and use when $h<$ SWALT

RLD1 Lift to drag ratio from $t_{0}$ to $M_{\infty}=1$

RLD2 Lift to drag ratio for $M_{\infty}<1$

RYDI Yaw to drag ratio from $t_{0}$ to $M_{\infty}=1$

RYD2 Yaw to drag ratio for $M_{\infty}<1$

HC $\varnothing \quad$ Lower altitude limit, ft, of calculations

HøUT Upper altitude limit, ft, of calculations. If $h>H \emptyset U T$ and NPASS $>0$ then skip trajectories are done 


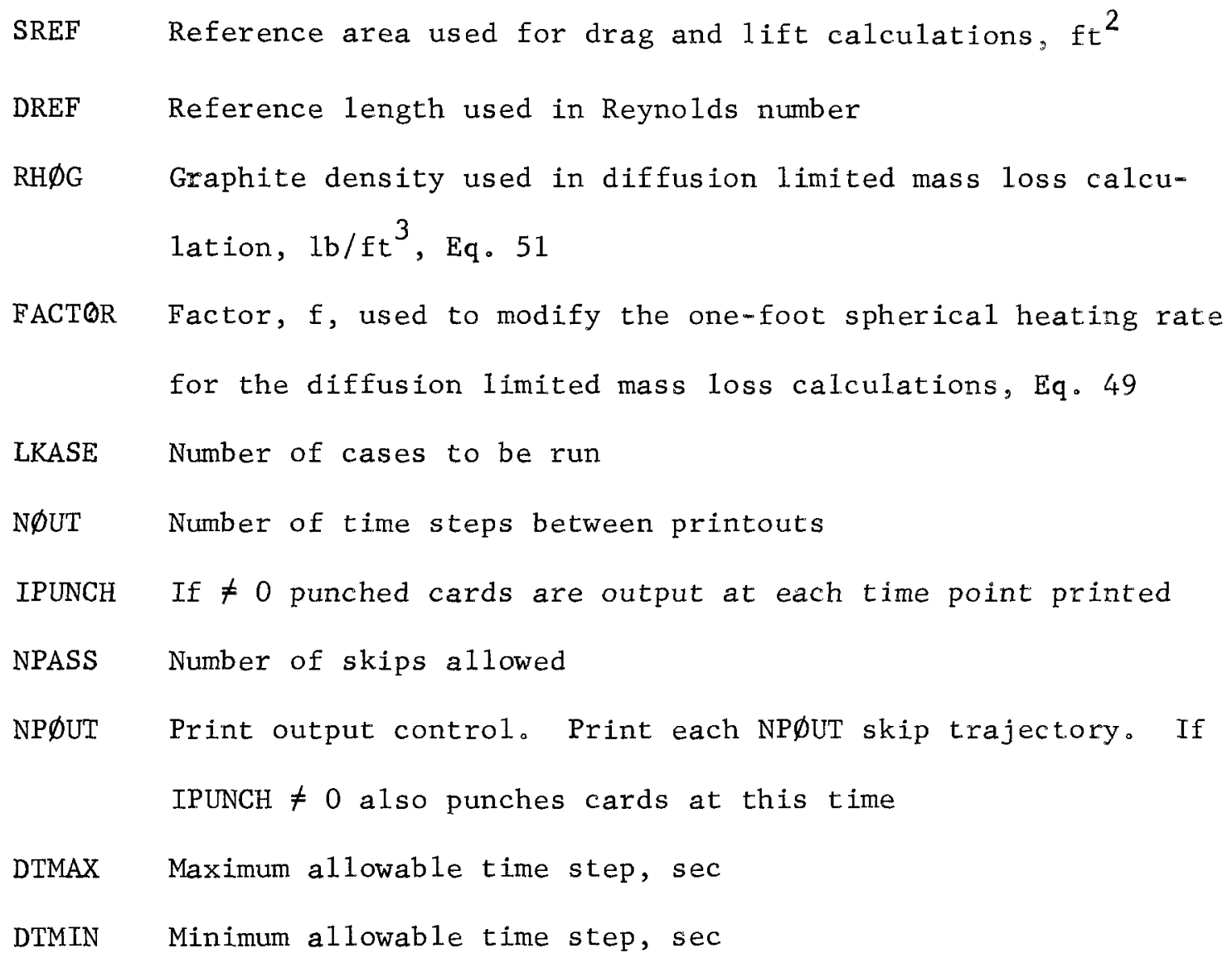

To signify the end of the INPUT data block the characters '\&END' are punched on a card. The above data block variables are essentially un* formatted, i。e., the order is immaterial and the variables are separated by commas and can appear anywhere on the card. An example is illustrated in Appendix II. Any variables not specified in the input either take on the initialized value in the program for the first case run or retain the value specified in the previous case. Following the namelist variables the various tables, controlled by JAER $\emptyset$, IAER $\varnothing$, SWMCH, SWALT, SKINFR, and DWT, are read in the following order. 
1. If $\operatorname{IAER} \emptyset<0$ and $\operatorname{JAER} \emptyset \neq 0$ then read and print $\mathrm{C}_{\mathrm{A}}=\mathrm{f}(\mathrm{h})$ table or

If $\operatorname{IAER} \emptyset>0$ and JAER $\emptyset \neq 0$ then read and print $\mathrm{C}_{\mathrm{A}}=\mathrm{f}\left(\mathrm{M}_{\infty}\right)$ table or If IAER $\emptyset=0$ then do not read tables in this section.

2. If $\mathrm{SWMCH}>0$ or SWALT $>0$ then read and print $\mathrm{C}_{\mathrm{A}}=\mathrm{f}\left(\mathrm{M}_{\infty}\right)$ table to be used when $M_{\infty}<$ SWMCH or $h<$ SWALT.

3. If SKINFR $>0$ then read and print $\mathrm{C}_{\mathrm{f}}=\mathrm{f}(\mathrm{h}, \mathrm{V})$ table。

4. If DWT $>0$ then read and print weight loss factor, $\frac{W}{W_{0}}=f(h)$ table.

The formats for all the above tables are the same. On the first card the number of points in the table is punched (format I3 right adjusted). For the $\mathrm{C}_{f}$ table two integers are punched (format $2 \mathrm{I3}$ ), the length of the $\mathrm{h}$ table first and the $\mathrm{V}$ table length second. On the next card follows the list of independent variables, six per card (format 6G12.8). For the $\mathrm{C}_{\mathrm{f}}$ tables the list of $h^{\prime}$ 's are first followed by the list of $V$ 's commencing on a new card. This is then followed, starting on a new card, by the dependent variables (e.g。, $C_{A}, C_{f}$, weight loss) with the same format as the independent variables. For the $\mathrm{C}_{\mathrm{f}}$ tables the sequence of the values of $\mathrm{C}_{\mathrm{f}}$ are $\mathrm{C}_{\mathrm{f}}\left(\mathrm{h}_{1}, \mathrm{~V}_{1}\right)$, $\mathrm{C}_{\mathrm{f}}\left(\mathrm{h}_{2}, \mathrm{~V}_{1}\right), \ldots-\mathrm{C}_{\mathrm{f}}\left(\mathrm{h}_{\mathrm{n}}, \mathrm{V}_{1}\right), \mathrm{C}_{\mathrm{f}}\left(\mathrm{h}_{1}, \mathrm{~V}_{2}\right), \mathrm{C}_{\mathrm{f}}\left(\mathrm{h}_{2}, \mathrm{~V}_{2}\right), \cdots \mathrm{C}_{\mathrm{f}}\left(\mathrm{h}_{\mathrm{n}}, \mathrm{v}_{\mathrm{i}}\right)$ 。 The independent variables must be in ascending order. The maximum number of points for the $C_{f}$ table is 25 values of $h$ and 10 values of $V$. All the other tables have a maximum dimension of 100 . 
If IPUNCH $=0$ in the INPUT data block, punched card output is obtained. At each time step printed (controlled by NøUT) a card is punched with the following variables on each card: $t$ sec, $h_{T_{S}} B t u / 1 b$, $\dot{\mathrm{q}}_{\mathrm{rad}} \mathrm{Btu} /\left(\mathrm{ft} \mathrm{t}^{2}-\mathrm{sec}\right), \dot{\mathrm{q}}_{\mathrm{c}} \mathrm{Btu} /\left(\mathrm{ft} \mathrm{t}^{2}-\mathrm{sec}\right), \dot{\mathrm{q}}_{\mathrm{FMF}} \mathrm{Btu} /\left(\mathrm{ft} \mathrm{t}^{2}-\mathrm{sec}\right), \mathrm{P}_{\mathrm{T}_{\mathrm{S}}} \mathrm{atm}, \mathrm{h}$ $\mathrm{Kft}$, and $\mathrm{V} f t / \mathrm{sec}$. The card format is (1X, F9.2, F10.1, 3F10.2, F10.5, F6.1, F7.0)。

\section{VI。 CONCLUSIONS}

The 3DOF computer code documented herein is well suited to the requirements of the Nuclear Safety Program; generating basic heating and trajectory data at a small cost. An orbital decay trajectory with $t \sim 1800 \mathrm{sec} f 1$ ight time can be generated at a cost of $\sim 50 \mathrm{c}$. The input requirements have been kept simple. The program is relatively small totaling $\sim 900$ cards allowing the addition of other options and capabilities, as they become necessary, in a relatively simple fashion。 
1. Nikke1, K。 G., "SPEED3D Computer Code Documentation," Lockheed Missile and Space Corp., Interdepartmenta1 Communication, LMSC/A869462, 14 Apri1 1970.

2. Hagan, J. C。 and Robertson, Mo Co, "Three-Degree-of-Freedom (3DOF) Reentry Body Simulation," Applied Physics Laboratory, The Johns Hopkins University Memo BBA-3-71-006, 8 March 1971。

3. "Users' Manual. Aerotherm Charring Material Thermal Response and Ablation Program, Version 3," Vo1。I and Vol。II, Aerotherm Report No。 UM 70-14, Apri1 1970.

4. Barber, L. A., et al., "A Guide to the Usage of the Standard Heat Transfer Program (PL/1)," APL/JHU Report BCP-441, Revision 1, Aug。1969。

5. Glover, L. S. and Hagan, J. C., "The Motion of Ballistic Missiles." Applied Physics Laboratory, The Johns Hopkins University, TG 1164, July 1971.

6. Matting, F. W., "Approximate Bridging Relations in the Transitional Regime Between Continuum and Free-Molecular F1ows," Jo Spacecraft and Rockets, Vo1.8, No.1, pp.35-40, Jan。1971.

7. Bal1, K。 J。 and Osborne, G. F。, Space Vehicle Dynamics, Oxford Univer = sity Press, London, 1967.

8. Heffron, W. G. and Watson, S. B., "Relationship Between Geographic and Inertial Coordinates," J. Spacecraft and Rockets, Vol。4, No。4, pp。 531-532, Apri1 1967. 
THE JOHNS HOPKINS UNIVERSITY APPLIED PHYSICS LABORATORY

SILVER SPRING. MARYLAND

9. U. S. Standard Atmosphere, 1962, U. S. Government Printing Office, Washington, D. C., Dec。1962.

10. Wittliff, C. E. and Curtis, J. T., "Normal Shock Wave Parameters in Equilibrium Air," Corne11 Aeronautical Lab., Inc. Report No. CAL-111, Nov. 1961; see also CAL Report No. AG-1729-A-2, Aug. 1962.

11. Ames Research Staff, "Equations, Tables, and Charts for Compressible Flow," NACA Report 1135, 1953.

12. Hilsenrath, J。H., et $a 1$, Tables of Thermodynamics and Transport Properties of Air, Argon, Carbon Dioxide, Carbon Monoxide, Hydrogen, Nitrogen, Oxygen and Steam, Pergamon Press, New York, 1960。

13. Perini, L. L., "Compilation and Correlation of Experimental, Hypersonic, Stagnation Point Convective Heating Rates," Applied Physics Laboratory, The Johns Hopkins University, ANSP-M-4, July 1972.

14. Sibulkin, M. J., "Heat Transfer Near the Forward Stagnation Point of a Body of Revolution," J. of the Aeronautical Sciences, Vol. 19, No.8, pp. 570-571, Aug. 1952.

15. Korobkin, I. and Gruenewald, K。 Ho, "Investigation of Local Laminar Heat Transfer on a Hemisphere for Supersonic Mach Numbers at Low Rates of Heat Flux," J. of the Aeronautical Sciences, Vol. 24, No. 3, pp. 188-194, March 1957。

16. Callis, L. B., "Time Axymptotic Solution of Blunt Body Stagnation Region Flows with Nongray Emission and Absorption of Radiation," NASA TR-R-299, 1968 。 
THE JOHNS HOPKINS UNIVERSITY APPLIED PHYSICS LABORATORY

SILVER SPRING MARYLAND

17. Olstad, W. B。, "Nongray Radiating Flow About Smooth Symmetric Bodies," AIAA Journal, Vo1。9, No。1, pp.122-130, Jan.1971。

18. Perini, L。 L。, "Comparisons of G。E。 and APL Updated Stagnation Point. Radiative Flux Calculations," APL/JHU Memo BHP-73-11, ANSP-019, May 3, 1973.

19. Perini, L。L。, "Review of Graphite Ablation Theory and Experimenta1 Data," Applied Physics Laboratory, The Johns Hopkins University, ANSP-M-1, Dec。1971。

20. Jensen, J。, Townsend, G。, Kork, J。 and Kraft, D。, Design_Guide to Orbital Flight, McGraw-Hil1 Book Co., Inc., New York, 1962.

21. Perini, L。 L。, "1962 Standard Atmosphere," APL/JHU Memo BHP-64-100 March 31, 1964. 


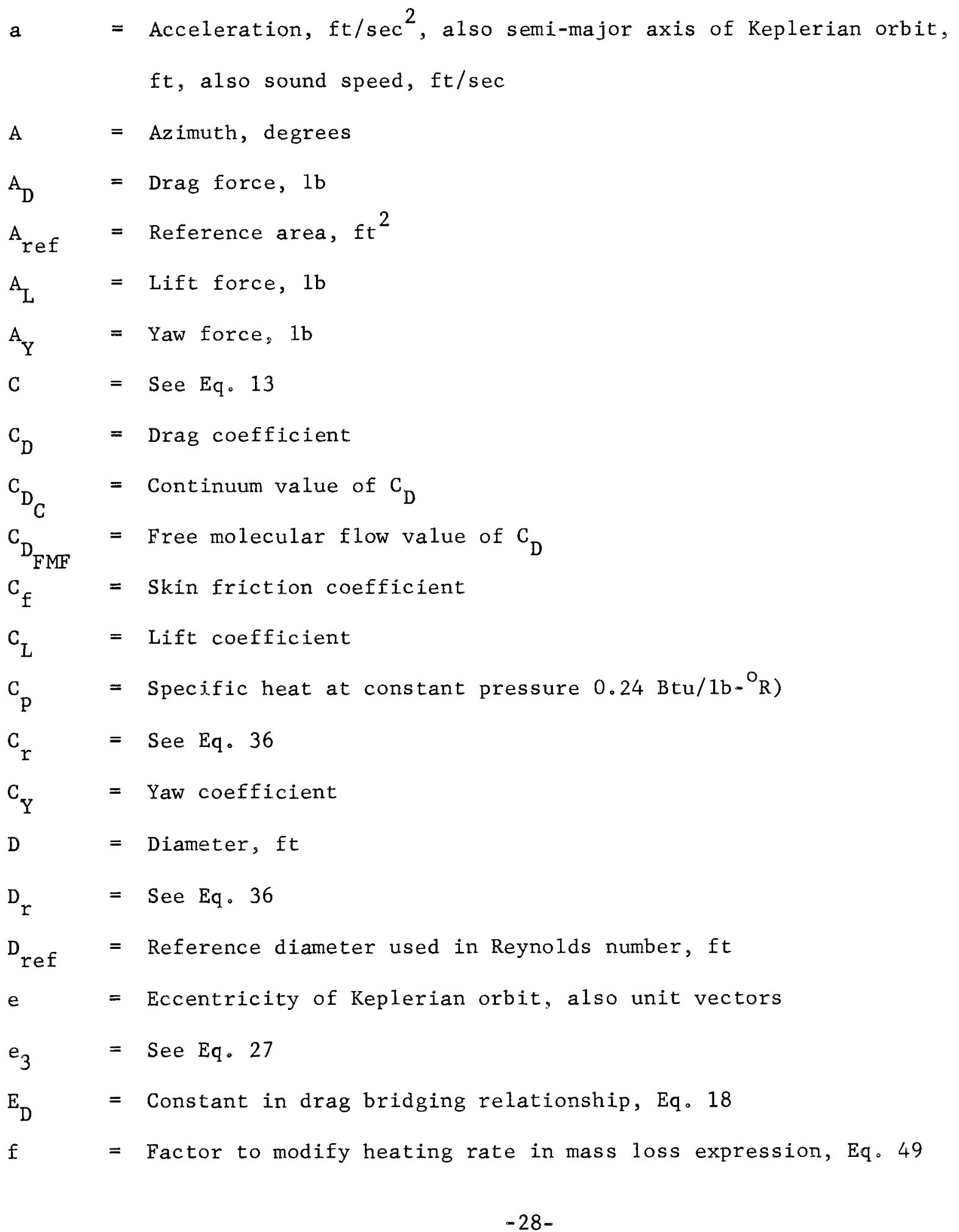


THE JOHNS HOPKINS UNIVERSITY APPLIED PHYSICS LABORATORY

SILVER SPRING. MARYLAND

$\mathrm{F} \quad=$ Force, $1 \mathrm{~b}$

$\mathrm{F}_{\mathrm{Ai}}=$ Aerodynamic forces, $i=r, \theta, \emptyset$

$\mathrm{F}_{\mathrm{g}_{i}} \quad=$ Gravity forces, $i=r, \theta$

$\mathrm{g}=$ Acceleration of gravity, ft/sec ${ }^{2}$

h $=$ Altitude, ft

$\mathrm{h}_{\mathrm{T}} \quad=$ Total enthalpy, Btu/1b, Eq. 31

i $=$ Orbit inclination

$\mathrm{J}=\mathrm{Joule}$ 's constant, $778.172 \mathrm{ft}-1 \mathrm{~b} / \mathrm{Btu}$

$\mathrm{K}_{\mathrm{N}}=$ Knudsen number, Eq. 33

L $\quad=$ Longitude, degrees

$\widetilde{\mathrm{L}}=$ Longitude measured from line of nodes, degrees

$\mathrm{m} \quad=$ Mass, $I \mathrm{~b}-\mathrm{sec}^{2} / \mathrm{ft}$

$\dot{\mathrm{m}}_{\mathrm{D}} \quad=$ Mass loss rate, $\mathrm{Eq} \cdot 47$

$\mathrm{M} \quad=$ Mach number, Eq. 30

$\mathrm{P} \quad=$ Pressure, $1 \mathrm{~b} / \mathrm{ft}^{2}$

$\mathrm{P}_{\mathrm{T}} \quad=$ Tota1 pressure, $1 \mathrm{~b} / \mathrm{ft}^{2}$

$\mathrm{q}=$ Dynamic pressure, $1 \mathrm{~b} / \mathrm{ft} \mathrm{t}^{2}, \mathrm{Eq} \cdot 35$

$\dot{\mathrm{q}}=$ Heat $\mathrm{flux}, \mathrm{Btu} /\left(\mathrm{ft} \mathrm{t}^{2}-\mathrm{sec}\right)$

$\dot{q}_{c} \quad=$ Convective continuum heat $f l u x, B t u /\left(f t^{2}-s e c\right)$

$\stackrel{\dot{q}}{\text { rad }}=$ Radiative heat $\mathrm{flux}, \mathrm{Btu} /\left(\mathrm{ft} \mathrm{t}^{2}-\mathrm{sec}\right)$

$\stackrel{\circ}{\text { FMF }}=$ Free molecular flow heat flux, Btu/ $\left(\mathrm{ft}^{2}-\mathrm{sec}\right)$

$r=$ Radius from earth's center to point mass, ft

$r_{a}=$ Apogee of Keplerian orbit, ft, Eq. 55

$r_{p} \quad=$ Perigee of Keplerian orbit, ft, Eq. 56 


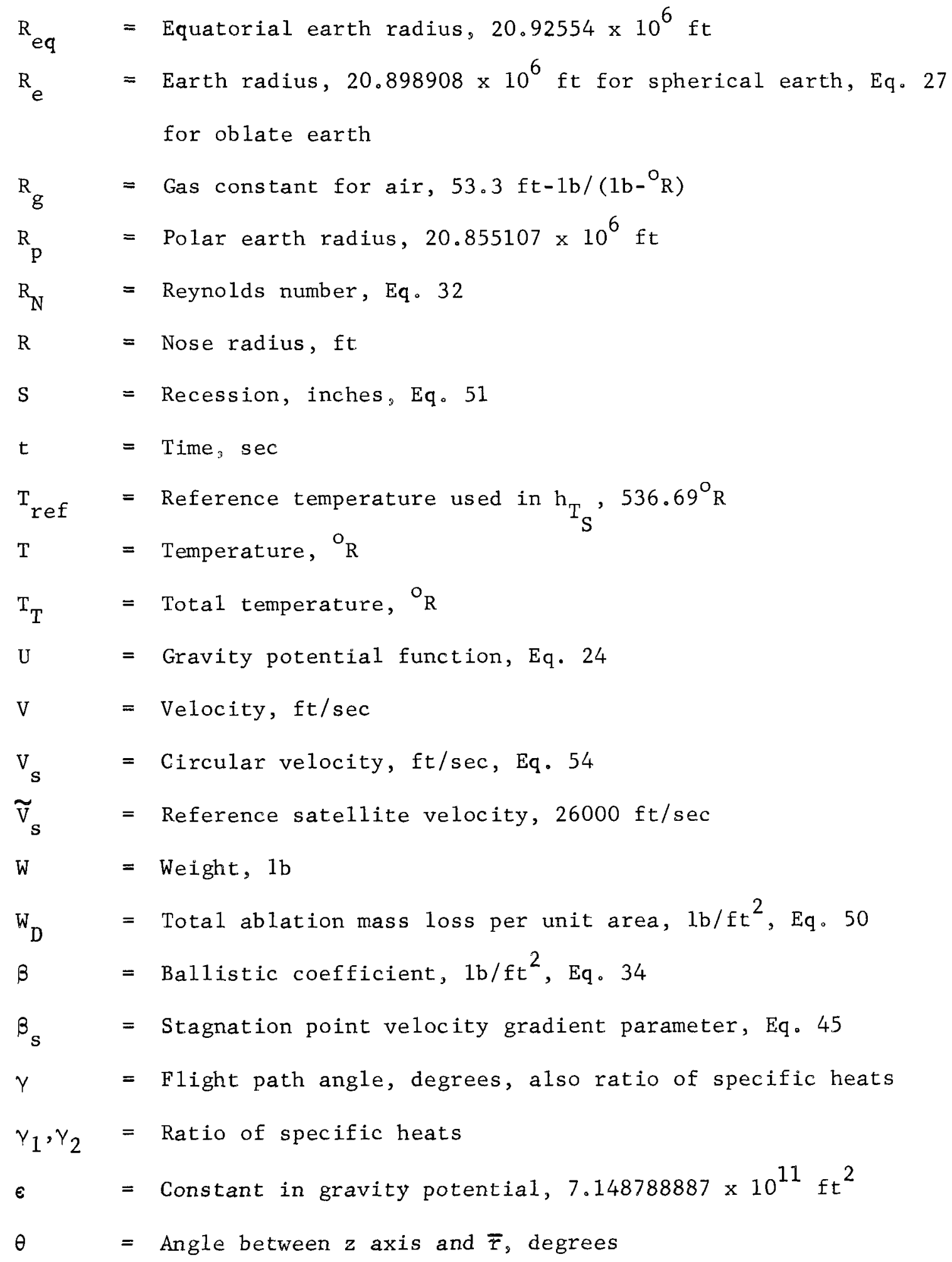


THE JOHNS HOPKINS UNIVERSITY APPLIED PHYSICS LABORATORY SILVER SPRING MARYLAND

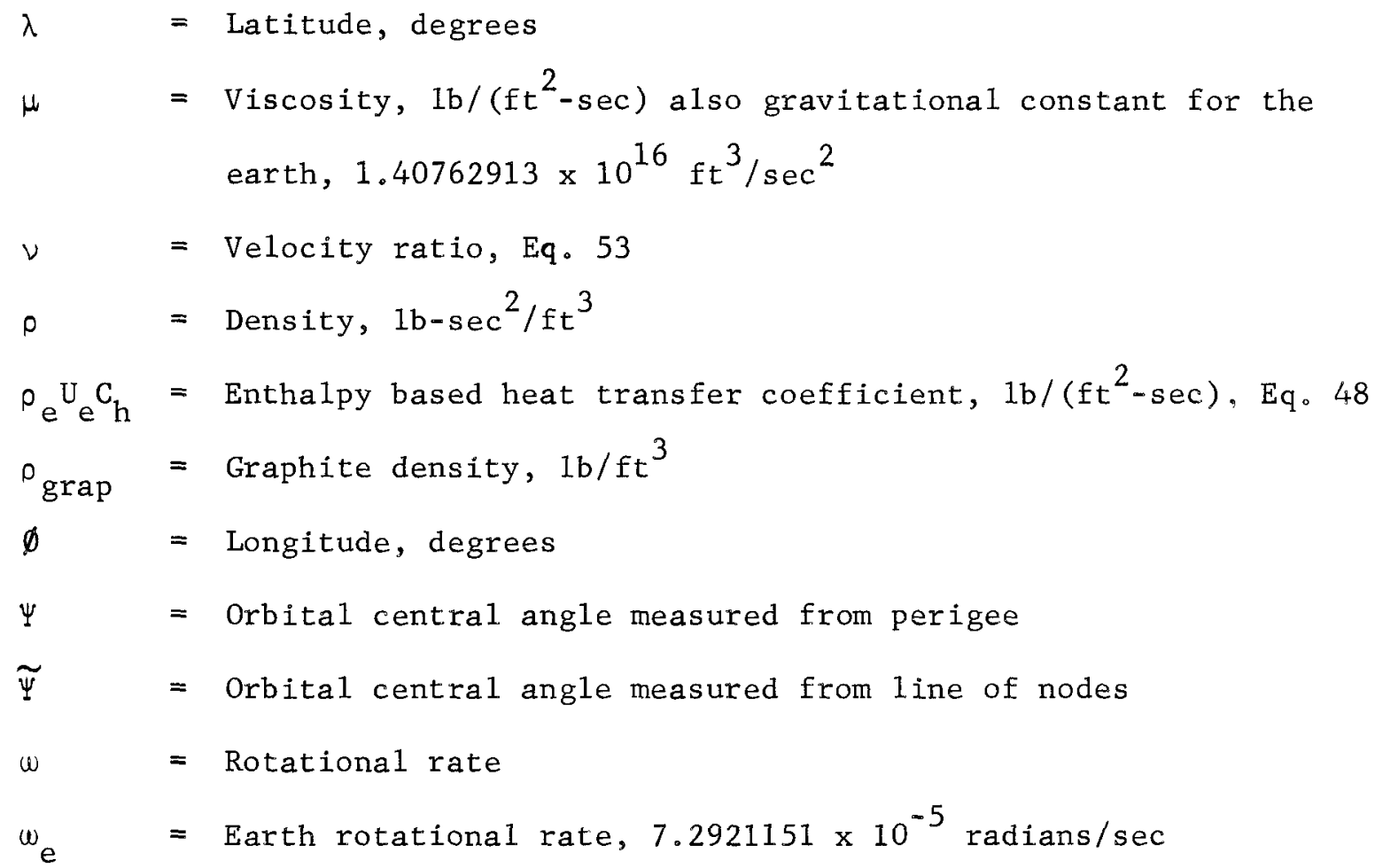

Superscripts

$\left(^{\circ}=\right.$ Total derivative with respect to time

()$^{\prime}=$ Inertial values

( $=$ Vectors

\section{Subscripts}

()$_{0}=$ Trajectory initial conditions

()$_{\mathrm{e}}=$ Trajectory exit conditions for skip calculations

()$_{\infty}=$ Free stream conditions

()$_{\mathrm{S}}=$ Stagnation conditions

()$_{2}=$ Conditions behind a normal shock

( $)_{\mathrm{g}}=$ Geodetic values

()$_{\mathrm{SL}}=$ Sea level conditions 
THE JOHNS HOPKINS UNIVERSITY APPLIED PHYSICS LABORATORY

SILVER SPRING MaryLAND

()$_{\mathrm{r}}=$ Component in $\mathrm{r}$ direction

( ) $\emptyset=$ Component in $\emptyset$ direction

( ) $\theta=$ Component in $\theta$ direction 
Table I。 Stagnation Point Radiative Flux Heating Rates, Btu/ $\left(\mathrm{ft}^{2}-\mathrm{sec}\right)$

\begin{tabular}{|c|c|c|c|c|c|c|c|c|}
\hline \multirow{2}{*}{$\begin{array}{c}\mathrm{U}_{\infty} \\
\text { Velocity } \\
\text { ft/sec }\end{array}$} & \multicolumn{8}{|c|}{$\mathrm{Z}$, Altitude, Kft } \\
\hline & 75 & 100 & 150 & 200 & 225 & 250 & 275 & 300 \\
\hline 26000 & $2300 *$ & $335^{* *}$ & $5.5^{*}$ & $.150^{*}$ & $.02^{*}$ & $.002^{*}$ & $.0002^{*}$ & $.00004^{*}$ \\
\hline 28000 & 5176.0 & 761.3 & 14.2 & .453 & .078 & .010 & .00088 & .0002 \\
\hline 30000 & 11611 & 1877 & 43.4 & 1.71 & .323 & .047 & .0043 & .0009 \\
\hline 32000 & 26249 & 5676 & 219.1 & 12.11 & 2.66 & .442 & 046 & .011 \\
\hline 34000 & 52807 & 14794 & 792.3 & 58.6 & 14.3 & 2.46 & .195 & .028 \\
\hline 36000 & $86000^{*}$ & 27609 & 1780.0 & 154.1 & 33.9 & 5.08 & .432 & .068 \\
\hline 38000 & $160000^{*}$ & $50000^{*}$ & 3261.0 & 276.0 & 62.6 & 10.0 & .903 & .154 \\
\hline 40000 & $260000^{*}$ & $74000^{*}$ & 5389.0 & 448 & 107 & 18.0 & 1.70 & .314 \\
\hline 42000 & $340000^{*}$ & $100000^{*}$ & 7772 & 675 & 169 & 29.4 & 2.86 & .563 \\
\hline 44000 & $440000^{*}$ & $130000^{*}$ & 10533 & 954 & 245 & 43.7 & 4.32 & .907 \\
\hline 46000 & $525000^{*}$ & $160000^{*}$ & 13564 & 1276 & 335 & 60.2 & 6.02 & 1.353 \\
\hline
\end{tabular}

${ }^{*}$ Callis computer code failed to give a solution. Values are based on extrapolations. 


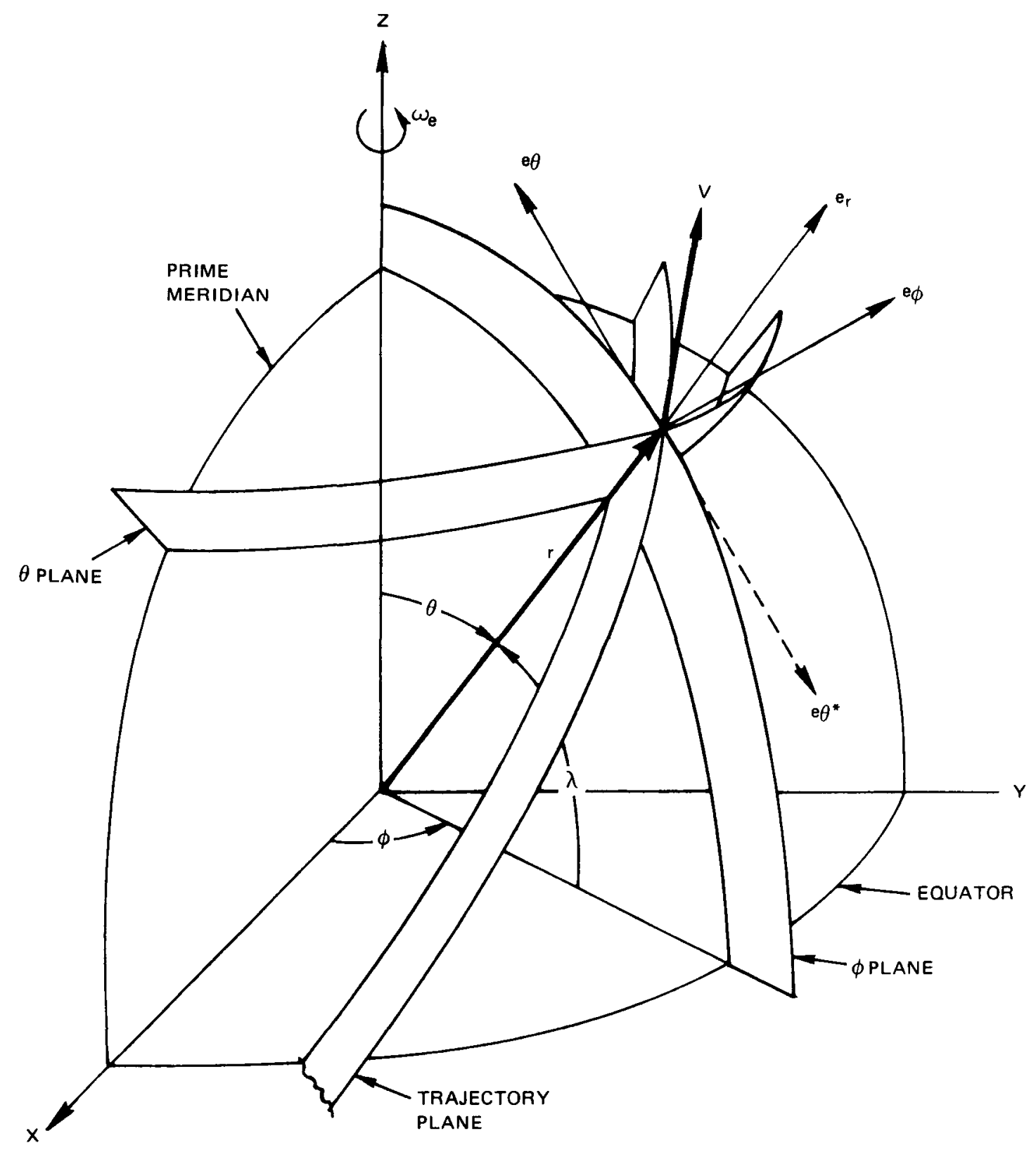

Fig. 1 COORDINATE SYSTEM 
THE JOHNS MOPKINS UNIVERSITY

APPLIED PHYSICS LABORATORY

SHLVER SPRING MARYLAND

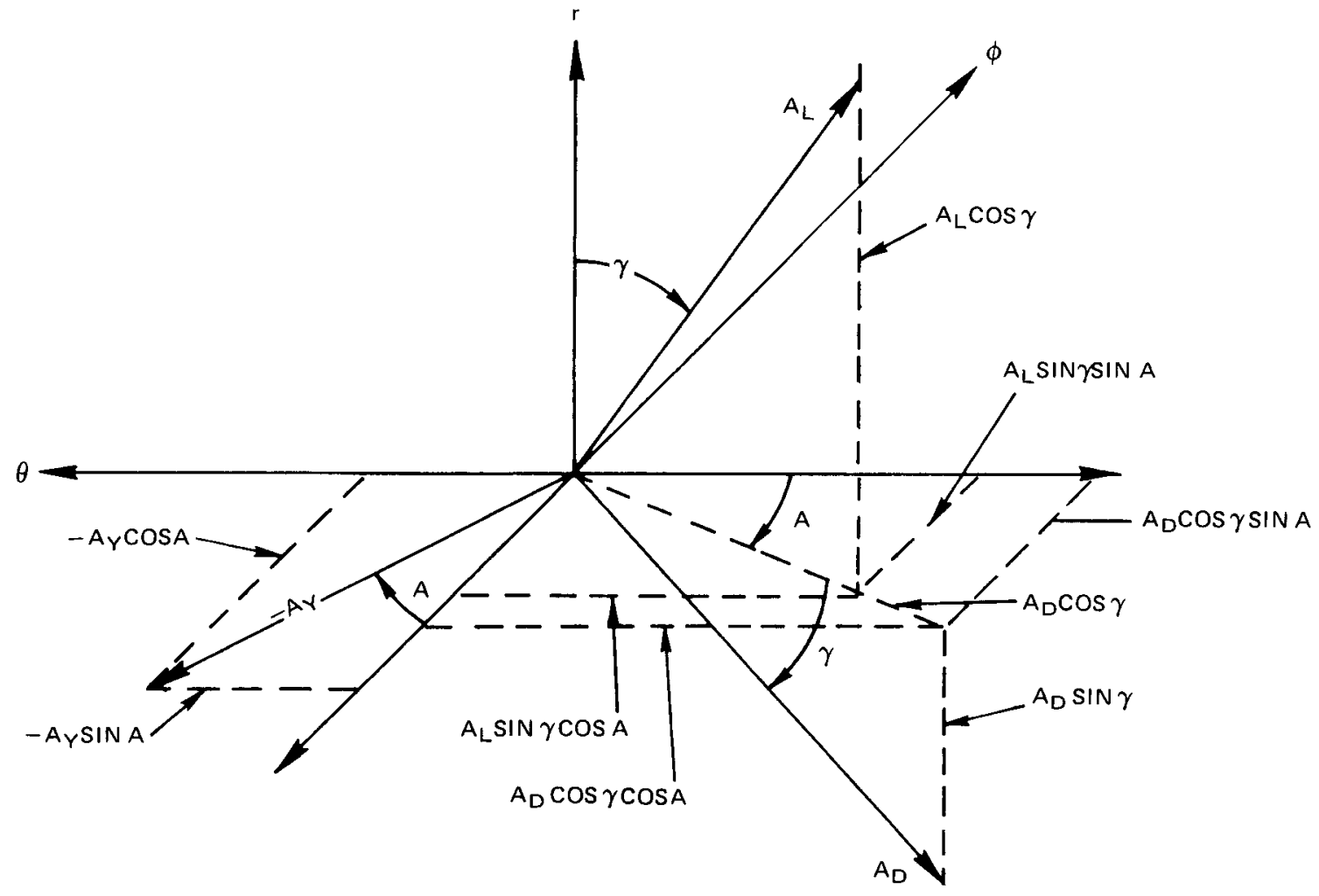

Fig. 2 AERODYNAMIC FORCE COMPONENTS 
THE JOHNS MOPKINS UNIVERSITY APPLIED PHYSICS LABORATORY SILVER SPRING MARYLAND

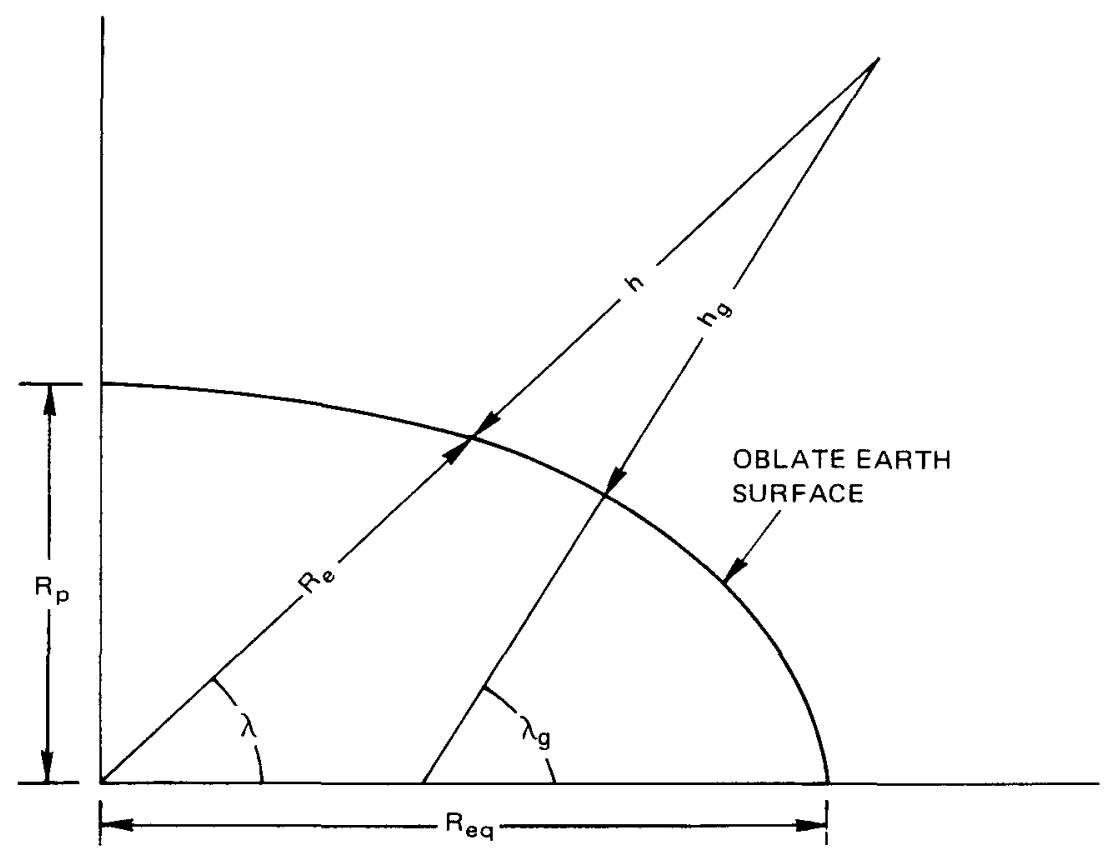

Fig. 3 RELATIONSHIP BETWEEN GEOCENTRIC $(\lambda, h)$ AND GEODETIC $\left(\lambda_{g}, h_{g}\right)$ LATITUDE AND ALTITUDE 


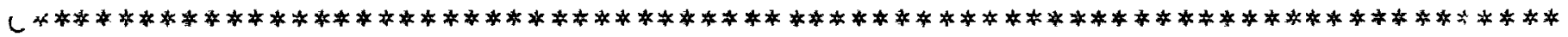

BLOCK DATA

DOUBLE PRECISION $Y$

COMAON /ATMOT/ Z (22),TME (22), E (21), PB (22), C1, C2, C3,

1

C7, C8, ZM, BO, GM, GAM, BST,GO, PO, WO, GO 1

COMMON/RADI/TQR $(12,8)$, TALR (8), TVER (12),LTV。LTZ

COMMON/FLOT/X $(71)$

COMMON/FIXED/I (22)

COMMON/DPRES/Y (14)

COMMON $/ \mathrm{TBLS} / \mathrm{W}(1085)$

$\mathrm{C}$

$\begin{array}{llllllll}24000 & 26000 & 28000 & 30000 & 32000 & 34000 & 36000 & 38000 \\ 40000 & 42000 & 44000 & 46000 & & & & \\ \text { DATA } & \text { TQR/ } & & & & \end{array}$

DATA

$$
\text { TQR/ }
$$

$11000.0 .2300 .0,5176.0,11611.0,26249.0,52807.0,86000.0,160000.0$ 。 * 260000.340000.0.440000.0.525000.0.

$2160.0335 .0,761.0,1877.0,5676.0,14794.0,27609.0 .50000 .0$ 。

*74000.0100000.0,130000.0,160000.0.

$3 \quad 2.2 .5 .5,14.2,43.4,219.1,792.3,1780.0,3261.0$,

$5389.7772 .0,10533.0 .13564 .0$. $.05, .150, .453,1.71,12.1,58.6,154.0 .276 .0$. $448.675 .0,954.0,127600$ 
$51.08140 \mathrm{E}-11,3.40513 \mathrm{E}-12,1.17620 \mathrm{E}-12 / . \mathrm{C} 8 / 3.28084514 /$

$6, \mathrm{C} 1 / 0.3048 /, \mathrm{C} 2 / 1.00 \mathrm{E}+03 /, \mathrm{C} 3 / 1.8 / . \mathrm{GO} 1 / 32.174 /, \mathrm{C} 7 / 1.00 \mathrm{E}-08 /$

$7 . \mathrm{ZM} / 9.00 \mathrm{E}+05 / \mathrm{RO} / 6.375605 \mathrm{E}+06 / \mathrm{GM} / 3.9862216 \mathrm{E}+14 / . \mathrm{GAM} / 1.4 /$

$8, \mathrm{RST} / 8.31432 / \mathrm{GO} / 9.80665 /, \mathrm{PO} / 2.11622 \mathrm{E}+03 /$, WO $/ 28.9644 /$ END

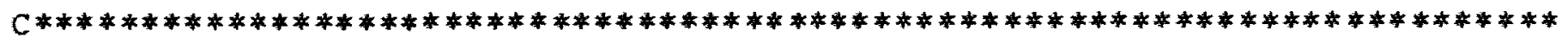

C MAIN PROGBAM

C

3D POINT MASS TRAJECTORY PROGRA

MODIFIED FOR AEC SAEETY ANALYSIS LLP 1972

KGN JULY 69

COMMON/DPRES/RE,H (5), AZR, GAMR, WE, T, GR, AD, AL, AY

COMMON/FLOT/THETO, PHIO,THETAX, PHIX, GO, MASS, RAD, RHO, WTMULT,

1 TOLD, VAIR, MACH, QBAR, REY, CD, CA, HJACK, VSOUND, TEMP, WO, SREF。

2 TFIL, WFIL, CAFIL, SKINFR, DWT, QC, QR, QDC, QDR, AZO, TO,

3 PRS, MOLH, CASE (17), QDFM, QPM, CDC, CDFU, RNOSE, ED, HODT, GAMI, VI,

4 AZI, XLAT,XLONG,DIFMD ,RANGE, RANGEO, HTS, RLD, RECS, DREF, RYD

COMMON / FIXED/I, NWT, NALT, NVEL, J ACK, NMACH, LNKT1, KOUT, NHCHEK,

1 NOUT, KJACK, IAERO, NCD, NMAC, ISWH, IOUT, IPASS, NPASS, IRUNCH, JDATE (3)

COMMON/TBLS/ DLWT (100), WALT (100), CATBL (100), ALTTBL (25),

$1 \operatorname{CASFTB}(25,10), \operatorname{TBLMAC}(100), V \operatorname{ELTBL}(10), \operatorname{CDTBL}(100), \operatorname{ALTBL}(100)$,

2 CDMTBL (100), TBLMA (100)

COMMON/RADI/TQR (12,8),TALR (8),TVER (12) ,LTV,LTZ

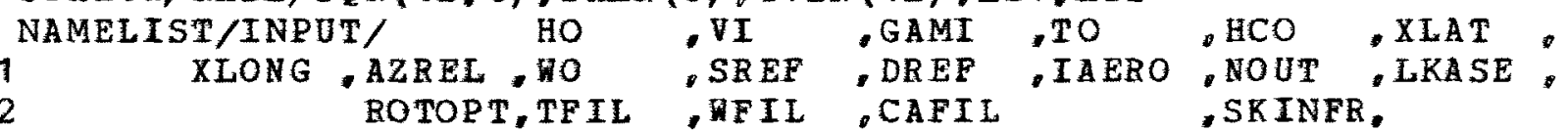

2 DUT, CDC, CDFH, RNOSE, ED,

3 VEEL ,GAMREL, IRI ,SWMCH, AZI, HOUT, IOBL, NPASS,

4 DTMAX, DTMIN JAERO, RANGEO, IPUNCH, SWALT, FACTOR,RHOG

5 .NPOUT, RLD 1, RLD2, RYD 1, BYD2

DOUBLE PRECISION RE,H, AZR, GAMR, WE, T, GR, GT, VR (5), VTH (5), VPH (5),

1 VRD (5), VTHD (5), VPHD (5) , XL,DT2, DT, THETA (5), PHI (5), HO, XMU, EPS,

$2 R E Q, R P O, R R O P, H R E X(5), B(5), B R E, A D, A L, A Y$, WEC , WE, COSG, SING

REAL MACH, MASS, MRAT, MOLW

DO $128 \mathrm{I}=1, \mathrm{LTV}$

DO $128 \mathrm{~J}=1, \mathrm{LTZ}$

$128 \operatorname{TQR}(I, J)=\operatorname{ALOG}(\operatorname{TQR}(I, J))$

NKAS $E=1$

CALL IDATE (JDATE)

C INITILTZE NAMELIST VARIABLES

RLD $1=0.0$

RLD 2 $=0.0$

$\mathrm{RYD} 1=0.0$

RY D $2=0.0$

HO $=400000.0$

$V I=25711.6$

$\mathrm{HCO}=115.0$

AZREL $=0.0$

พO $=1.0$

$S R E F=1.0$

DREF $=1.0$ 


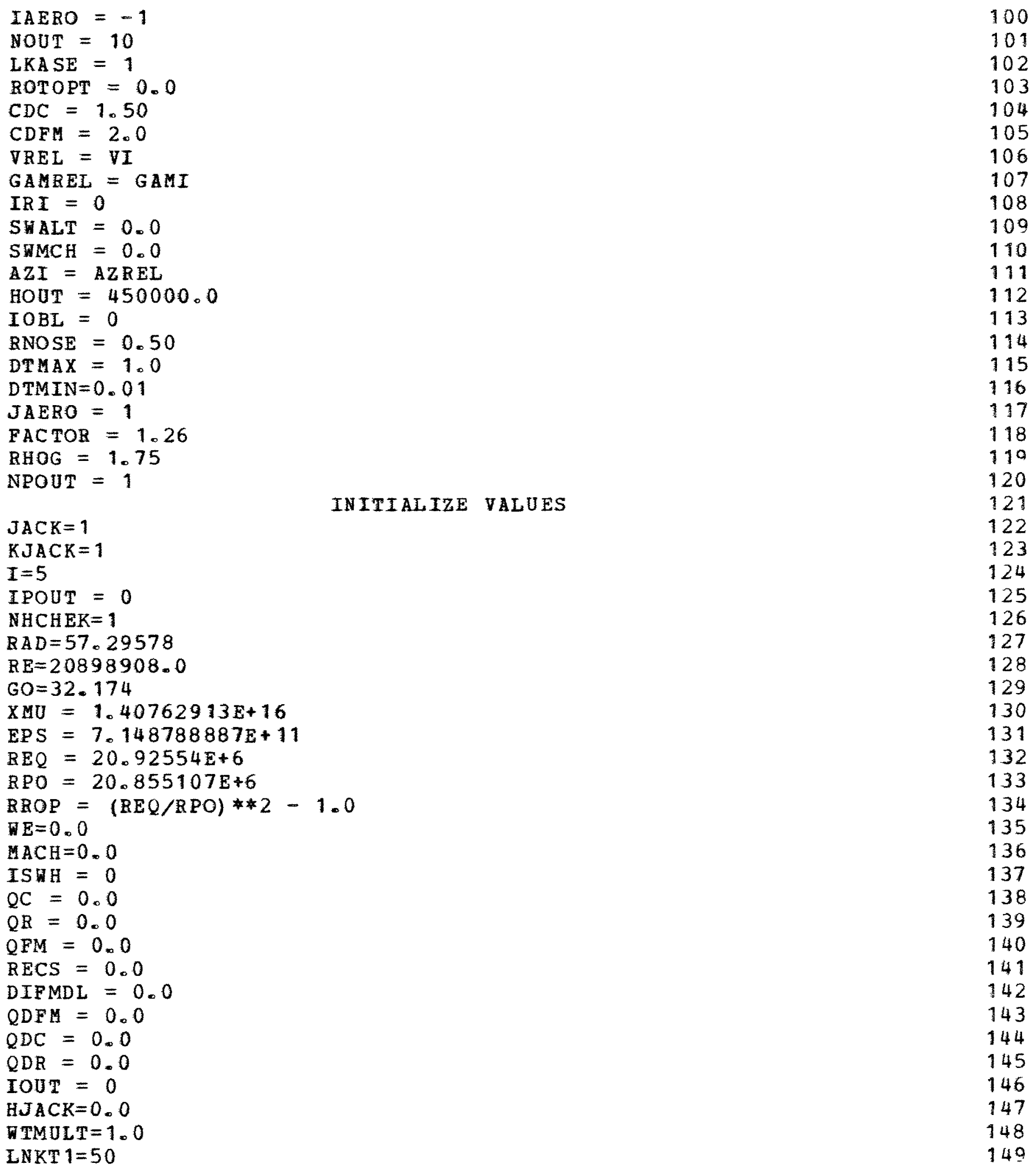


C IPASS $=0$

READ TITLE CARD

READ $(5,425) \mathrm{CASE}$

151

READ (5,INPUT)

152

RLD $=$ RLD 1

RYD $=$ RYD1

153

$\mathrm{HCOX}=\mathrm{HCO}$

154

KOUT $=$ NOUT

C IF JAERO = 0 OSE LAST AERO TABIE
IF (JAERO.EQ.0) GO TO 53

155

156

157

IF (JAERO。EQ。0) GO TO 53

WRITE $(6,450)$ CASE, JDATE

HRITE $(6,485)$

C IF IAERO = 0 USE BRIDIGING EQUATION IN CALC

IF (IAERO) $51,50,45$

C $\triangle E R O$ TABLE CA = F (ALT) IAERO = -1

51 READ $(5,435)$ NCD

READ (5,440) (ALTBL (L) $, L=1, N C D)$

$\operatorname{READ}(5,440) \quad(\mathrm{CD} P \mathrm{BL}(\mathrm{L}): L=1, \mathrm{NCD})$

WRITE $(6,40)$

WRITE $(6,41)$ ((CDTBL (L), ALTBL (L)), L=1, NCD)

GO TO 50

C AERO TABLE CA $=$ F (MACH)

IAERO $=+1$

45 READ $(5,435) \mathrm{NMACH}$

READ $(5,440)$ (TBLMAC (L), L=1, NMACH)

$\operatorname{READ}(5,440)$ ( (CATBL (L) $\quad 0 L=1, N \mathrm{NACH})$ )

WRITE $(6,46)$ NMACH

VRITE $(6,47)$ (T BLMAC (L), $L=1, N M A C H)$

WRITE $(6,47)$ (CATBL (L) .L=1,NMACH)

C LOW MACH NO AERO TABLE $C A=F$ (MACH) SWMCH $>=0.0$ OR SWALT $>=0.0$

158

159

160

161

162

163

164

165

166

167

168

169

170

171

172

173

174

175

176

177

178

50 IF $((S W M C H . L E 。 0.0)$ AND。(SHALT。LE.0.0)) GO TO 53

179

READ (5.435) NMAC

$\operatorname{READ}(5,440)$ (TBLHA (L), L=1, NMAC)

180

181

READ $(5,440)$ (CDMTBL (L), $L=1$, NMAC)

182

WRITE $(6,491)$ SWMCH,SWALT

WRITE $(6,41)(($ CDMTBL (L) , TBLMA (L)), L= 1, NMAC)

C

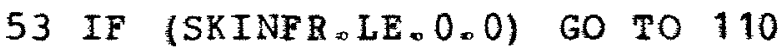

SKIN FRICTION - F $(H, V)$

183

184

185

186

READ $(5,435)$ NALT, NVEL

READ $(5,440)$ (ALTTBL $(K), K=1, N A L T)$

READ $(5,440)$ (VELTBL (J), J 3 , NVEL)

$\operatorname{READ}(5,440)($ (CASFTB $(K, J), K=1, N A L T), J=1, N V E L)$

NRITE $(6,46)$ NALT, NVEL

WRITE $(6,56)$ (ALTTBL $(K), K=1, N A L T)$

WRITE $(6,56)$ (VELTBL (J), J $=1, N$ VEL)

DO $57 \mathrm{~J}=1, \mathrm{NVEL}$

57 RITE $(6,58)$ (CASFTB $(\mathrm{K}, J), K=1, N$ ALT)

C

110 IF (DWT.LE.0.0) GO TO 240

WEIGHT LOSS - ALTITUDE

187

188

189

190

191

192

193

194

195

196

197

READ $(5,435)$ NET

$\operatorname{READ}(5,440)(\mathrm{NALT}(I) \triangleq I=1, N$ NT) 
READ (5,440) (DLWT (I), I=1,NWT) 200

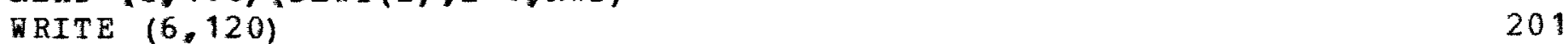

WRITE $(6,125) \quad 202$

WRITE $(6,495)$ (NALT (I) , I=1,NWT)

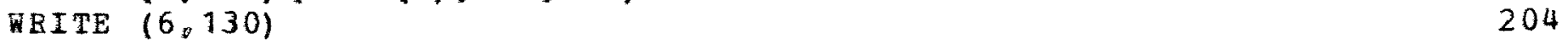

WRITE $(6,490)$ (DLWT (I), I=1,NWT)

$\mathrm{C}$

ROTATING EABTH OPTION 206

$240 I=5$

$\mathrm{BECSL}=\mathrm{RECS}$

207

QDFMLS $=$ QDFM

208

209

QDCLS $=$ QDC

210

QDRLS $=$ QDR

211

IF (ROTOPT.NE。0) WE $=0.7292115 \mathrm{E}-4 \quad 212$

IF (IOBL.EQ.0) GO TO 603

$R E=R E Q /(D S Q R T(1.0+R R O P * \operatorname{SIN}(X L A T / R A D) * 2))$

$\mathrm{HRE}=\mathrm{HO}+\mathrm{RE}$

$\mathrm{GR}=\mathrm{XMU} *(1.0 * \operatorname{EPS} *(1.0-3.0 * \mathrm{SIN}(\mathrm{XLAT} / \mathrm{RAD}) * 2) / \mathrm{HRE} * 2) / \mathrm{HRE} * 2$

213

214

215

GO TO 604

$603 \mathrm{HRE}=\mathrm{HO}+\mathrm{RE}$

$G R=G O *(R E / H R E) * 2$

216

217

218

219

220

604 VCIRC $=$ DSQRT (GR*HRE)

221

IF (IRI. EQ.0) GO TO 43

222

VO $=$ VEEL

GAMO = GAMREL

223

$\mathrm{AZO}=\mathrm{AZREL}$

$\mathrm{XL}=\mathrm{XLAT} / \mathrm{RAD}$

C1 $1=\mathrm{HRE} * \mathrm{HE} * \mathrm{DCOS}(\mathrm{XL}) / \mathrm{VREL}$

$V I=\nabla R E L * S Q R T(1.0+C 1 * 2 * 2.0 * \operatorname{COS}(G A * R E L / R A D) * S I N(A Z R E L / R A D) * C 1)$

224

225

226

GAMI = ARSIN (VREL*SIN (GAMREL/RAD) /VI) *RAD

227

$C 2=D \operatorname{COS}(A Z R / R A D)$

228

229

$C 3=1.0 E 12$

IF (ABS (AZREL-90.0).GE.0.0001) C3=TAN (AZEEL/RAD)

230

231

$A Z I=A T A N(C 3+C 1 / C O S(G A M R E L / B A D) / C 2) * R A D$

GO TO 44

$43 \mathrm{C} 1=\mathrm{HRE} * \mathrm{WE} * \mathrm{COS}(\mathrm{XLAT} / \mathrm{RAD}) / \mathrm{VI}$

VO $=V I * S Q R T(1.0+C 1 * 2-2.0 * \operatorname{COS}(G A M I / R A D) * S I N(A Z I / R A D) * C 1) \quad 235$

GAMO $=$ VI*SIN $(\mathrm{GAMI} / \mathrm{RAD}) /$ VO

GAMO = ARSIN $(G A M O) * \operatorname{RAD}$

$A Z O=S I N(A Z I / R A D)-C 1 / \operatorname{COS}(G A M I / R A D)$

232

233

234

237

$A Z B=\operatorname{COS}(A Z I / R A D)$

238

239

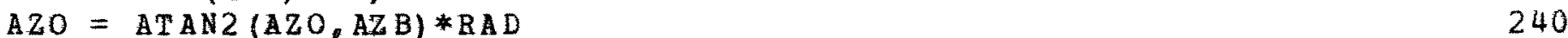

44 IF (IPOUT.EQ.0) GO TO 131

IF (IPOUT.NE。 1 ) GO TO 132

241

242

243

131 IPOUT $=1$

WRITE INITIAL CONDITIONS-

TEITE $(6,450)$ CASE, JDATE

244

245

WRITE $(6,475)$

IPP1 = IPASS +1

IF (NPASS。GT。0) WRITE $(6,476)$ IPP1

WRITE $(6,492)$ VO ,VI,GAMO ,GAMI, AZO, AZI,TO, WO, 
1 HO, XLAT, XLONG, SREF, DREF, RLD 1, RLD2, BYD1, RYD2, FACTOR, RHOG 250 WRITE $(6,486) \quad 251$

WRITE $(6.487)$ VCIRC

IF (IOBL。EQ.1) WRITE $(6,493)$ RPO,BEQ 253

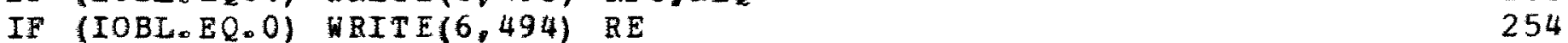

IF (ROTORT.NE.0.0) NRITE $(6,499)$ WE 255

IF (ROTOPT。EQ。0.0) VRITE $(6,496) \quad 256$

WRITE $(6,497)$ NOUT,DTMAX,DTMIN, HCO,HOUT 257

IF (IAERO.EQ.0) WRITE $(6,498)$ CDC,ED,CDFM, BNOSE

WRITE $(6,127) \quad 259$

C

$132 \mathrm{GAMR}=\mathrm{GAMO} / \mathrm{RAD}$

VARIABLE SETUP 260

(1)

$\mathrm{AZR}=\mathrm{AZO} / \mathrm{BAD} \quad 262$

$\begin{array}{lr}\text { MASS }=\text { WO } / G O & 263\end{array}$

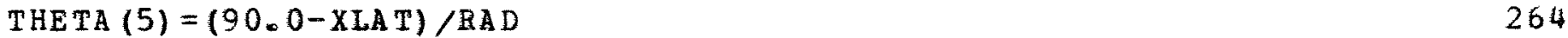

PHI (5) =XLONG/BAD $\quad 265$

$\begin{array}{lr}H(5)=\text { HO } & 266\end{array}$

$\begin{array}{lr}\mathrm{HREX}(5)=\mathrm{HO}+\mathrm{RE} & 267\end{array}$

$\mathrm{T}=\mathrm{TO} \quad 268$

TLA ST=TO $r$

$\begin{array}{lr}\text { THETO=THETA (5) } & 270\end{array}$

PHIO=XLONG /RAD 271

$\mathrm{C}$

$\operatorname{VR}(5)=V O * D S I N(G A M R)$

IN ITIAL VELOCITY COMPONENTS

272

273

$\operatorname{VTH}(5)=V O * D C O S(G A M R) * D C O S(A Z R) \quad 274$

$\nabla P H(5)=\nabla O * D C O S(G A M R) * D S I N(A Z R) \quad 275$

$\mathrm{C}$

INTEGRATION LOOP 276

$\begin{array}{lr}\text { GO TO } 265 & 277\end{array}$

255 DT $2=D T$

$260 I=I+1$

$\operatorname{VR}(I)=\operatorname{VR}(1)+\operatorname{VRD}(I-1) * \mathrm{DT} 2$

$\mathrm{VTH}(I)=V T H(1)+\nabla T H D(I-1) * \mathrm{DT} 2$

$V P H(I)=V P H(1)+V P H D(I-1) * D T 2$

$\operatorname{HREX}(I)=\operatorname{HREX}(1)+\mathrm{VR}(I-1) * \mathrm{DT} 2$

THETA $(I)=\operatorname{THETA}(1)-\operatorname{VTH}(I-1) * \operatorname{DT} 2 / \mathrm{HREX}(\mathrm{I}-1)$

$\operatorname{PHI}(I)=\operatorname{PHI}(1)+\mathrm{VPH}(I-1) * \operatorname{DT} 2 / \operatorname{HREX}(I-1) / \operatorname{DSIN}(T H E T A(I-1))$

278

279

280

281

282

283

284

285

286

287

IF (IOBL.EQ.0) GO TO 600

$X L=1.5707963-$ THETA (I)

288

$\mathrm{BE}=\mathrm{REQ} / \mathrm{DSQRT}(1.0+\mathrm{RROP} * \mathrm{DSIN}(\mathrm{XL}) * 2) \quad 289$

HRE $=$ HREX (I)

IF (NHCHEK.NE。2) H(I) = HRE-RE

$\mathrm{GR}=\mathrm{XMU} *(1.0+\operatorname{EPS} *(1.0-3.0 * \mathrm{DSIN}(\mathrm{XL}) * 2) / \mathrm{HRE} * 2) / \mathrm{ARE} * 2$

290

291

$G T=2.0 * X M U * E P S * D S I N(X L) * D C O S(X L) / H B E * 4$

292

293

GO TO 601

204

295

296

$\mathrm{H}(\mathrm{I})=\mathrm{HRE}-\mathrm{RE}$

$\begin{array}{rr}G R=G O *(R E / H R E) * 2 & 297 \\ G T=0.0 & 298\end{array}$

601 CONTINUE 
$\begin{array}{lr}\text { VAIR }=\text { VTOT } & 300\end{array}$

GAMR = DATAN(VR(I) /DSQRT (VTH (I)*2+VPH (I)**2))

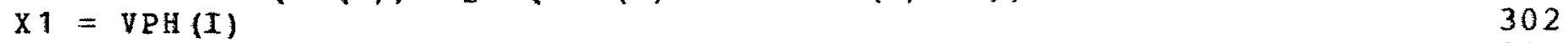

$\begin{array}{lr}X 2=V \mathrm{TH}(\mathrm{I}) & 303\end{array}$

$\begin{array}{lr}X 3=A Z M U T H(X 1, X 2) & 304\end{array}$

$\begin{array}{lr}A Z R=X 3 & 305\end{array}$

C 1962 ATMOSPHERIC PROPERITIES 306

$\begin{array}{lr}\mathrm{HHHH}=\mathrm{H}(\mathrm{I}) & 307\end{array}$

CALL ATM (HHHH, PRS, TEMP, MOLW, VSOUND,RHO) 308

CALL CALC

IF (NHCHEK。EQ。2) GO TO 320

C EQUATIONS OF MOTION IN SPHERICAL COORDINATES

WEC $=$ WE*DCOS (THETA (I))

WES $=$ WE*DSIN (THETA (I))

$H R T=H R E * D T A N(T H E T A(I))$

$\operatorname{COSG}=\operatorname{DCOS}(G A M R)$

SING $=$ DSIN (GAMR)

$\operatorname{VRD}(I)=(\mathrm{VTH}(I) * 2+\mathrm{VPH}(I) * 2) / \mathrm{HRE}-\mathrm{AD} * \mathrm{SING}-\mathrm{GR}$

$2+2.0 * V P H(I) * W E S+H R E * W E S * W E S+A L * C O S G$

$\operatorname{VTHD}(I)=-\mathrm{VPH}(\mathrm{I}) * 2 / \mathrm{HRT}-\mathrm{AD} * \operatorname{COSG} \mathrm{BCOS}(\mathrm{AZR})-\mathrm{VR}(\mathrm{I}) * \mathrm{VTH}(\mathrm{I}) / \mathrm{HRE}$

$1-2.0 * V P H(I) * V C D-H R E B S * W E C-A L * S I N G * D C O S(A Z R)-G T$

$2-A Y * D S I N(A Z R)$

VPHD (I) $=(\mathrm{VTH}(\mathrm{I}) * \mathrm{VPH}(\mathrm{I})) / \mathrm{HRT}-\mathrm{VR}(\mathrm{I}) * \mathrm{VPH}(\mathrm{I}) / \mathrm{HRE}$

$1-A D * C O S G * D S I N(A Z R)+2.0 *(V T H(I) * W E C-V R(I) * W E S)$

$2-A L * S I N G * D S I N(A Z R)+A Y * D C O S(A Z R)$

GO TO $(260,260,255,270,315)$. I

$270 \operatorname{VR}(5)=\operatorname{VR}(1)+D T *(\operatorname{VRD}(1)+2.0 *(\operatorname{VRD}(2)+\operatorname{VRD}(3))+\operatorname{VRD}(4)) / 6.0$

$\mathrm{VTH}(5)=\mathrm{VTH}(1)+\mathrm{DT}$ (VTHD (1) + 2.0* (VTHD (2) + VTHD (3)) + VTHD (4) $/ 6.0$

$V P H(5)=V P H(1)+D T *(V P H D(1)+2.0 *(V P H D(2)+V P H D(3))+V P H D(4)) / 6.0$

THETA $(5)=\operatorname{THETA}(1)-\mathrm{DT} *(\mathrm{VTH}(1) /(\operatorname{HREX}(1))+2.0 *(\mathrm{VTH}(2) /(\operatorname{HREX}(2))+$

309

310

311

312

313

314

315

316

317

318

319

320

321

322

323

324

325

326

327

328

32 ㅇ

330

331

332

333

334

335

336

337

IF (IOUT.EQ.1) GO TO 272

IF (H (5)。LT。HOUT) GO TO 271

HCO $=$ HOUT

IOUT $=1$

$272 \mathrm{DELH}=\mathrm{HCO}-\mathrm{H}(5)$

GO TO 273

$271 \mathrm{DELH}=\mathrm{H}(5)-\mathrm{HCO}$

273 IF (ABS (DELH) $: L E \circ 5.0$ ) GO TO 285

$I F$ (DELH) $280,285,290$

338

339

340

341

342

343

344

345

346

347

348

349 
GO TO 260

285 NHCHEK $=2$

$\mathrm{H}(5)=\mathrm{HCO}$

352

$\mathrm{T}=\mathrm{T}+\mathrm{DT}$

353

IF (NHCHEK。EQ.2) GO TO 265

354

$290 I=5$

$\mathrm{T}=\mathrm{T}+\mathrm{DT}$

GO TO 265

C

$315 \mathrm{DTSUB}=.01 *(\mathrm{VAIR}+2000.0) / \mathrm{DSQRT}(\operatorname{VRD}(I) * 2+\operatorname{VTHD}(\mathrm{I}) * 2+\operatorname{VPHD}(\mathrm{I}) * 2)$

$\mathrm{DT}=\mathrm{DTSUB}$

IF (DTSUB。GT.DTMAX) DT=DTMAX

IF (DTSUB。LT。DTMIN) DT =DTMIN

$\mathrm{DT} 2=\mathrm{DT} / 2.0$

$\mathrm{C}$

C --- INT EGRAT ION S- - -

OUTPUT CALCULATIONS

355

356

357

358

359

360

361

362

363

364

365

$320 \operatorname{IF}((H(5)=L T .200000 .0)$.AND。(IPOUT.NE.1)) GC TO 137

DELT $=\mathrm{T}-\mathrm{TLAST}$

HHH $=\mathrm{H}(5)$

HTS $=$ VAIR*2/50062.7+0.24*(TEMP-536.69)

C HEATING RATES FOR A 1-FT SPHERE。COLD MALL

C RADIATION - TABULAR VALUES FROM MODIFIED CALLIS CODE - 11/3/72-LLP

366

367

368

369

370

371

372

$Q D R=0.0$ ONE FOOT SPHERE

IF (VAIR.LT.24000.) GO TO 124

IF (HHHH.LT.75000.0) GO TO 124

$Q D R=P I F 11$ (VAIR, HHHH, TVER, LTV, TALE, LTZ, TQR, LTV, LTZ)

$Q D R=\operatorname{EXP}(Q D R)$

124 IF $(\mathrm{MACH}, \mathrm{GT}$.6。0) GO TO 121

C SIBULKIN NTH GAMA $=1.2$, SUPERSONIC \& SUBSONIC

$\mathrm{GAM}=1.2$

$A=1.0+(G A M-1.0) * M A C H * 2 / 2.0$

TS $=$ TEMP A

VISS $=9.898 \mathrm{E}-7 *(\mathrm{TS} / 1.8) * 1.5 /(110.4+\mathrm{TS} / 1.8)$

$\mathrm{P} 2=\mathrm{PBS}$

IF (MACH.LE. 1.0) GO TO 122

C SUPERSONIC FLOW

TEMZ $=$ GAM*MACH* *2 $-(G A M-1.0) / 2.0$

$\mathrm{P} 2=\mathrm{PRS} * 2.0 * \mathrm{TERZ} /(\mathrm{GAM}+1.0)$

$\mathrm{XM} 2=\mathrm{SQRT}(\mathrm{A} / \mathrm{TEMZ})$

$A=1.0+(G A M-1.0) * X M 2 * 2 / 2.0$

373

374

375

376

377

378

379

380

381

382

383

384

385

386

387

388

389

390

391

$122 \mathrm{PS}=\mathrm{P} 2 * \mathrm{~A} *(\mathrm{GAM} /(\mathrm{GAM}-1.0))$

RHOS $=$ PS $/$ TS $/ 53.3$

$B E T Z=1.1$

IE (MACH.LT.4.98)

$1 \mathrm{BETZ}=2.740409+\mathrm{MACH} *(-0.7121196+\mathrm{MACH} *(-0.125607+$

$1 \quad \mathrm{ACH} *(0.0978086-\mathrm{MACH} * 0.01148119)))$

$\mathrm{QDC}=0.945 * \mathrm{SQRT}(\mathrm{RHOS} * \mathrm{VISS} * \mathrm{BETZ} * \mathrm{VAIR} / 2.0) * \mathrm{HTS}$

GO TO 123

C HYPERSONIC FLON (DETRA,KEMP \& RIDDEL) 
$121 C 1=17600.0$

$C 2=3.15$

$Q D C=C 1 *((B E O * G 0 / 0.07647) * 0.50) *(V A I R / 26000.0) * C 2$

401

402

C FREE MOLECDLAE FLOW

123 QDFM $=$ RHO $($ VAIR* *3) $/ 2.0 / 778.0$

C ESTIMATE OF SUREACE RECESSION-DIFFUSION CONTROL

403

404

QDT $=$ QDC*FACTOR

IF (QDT. LE.0.0) GO TO 126

IF (QDFM/QDT.LT.10.0)

$1 Q D T=Q D T *(1.0-\operatorname{EXP}(-Q D F M / Q D T))$

DIFMD $=0.1725 * Q D T / H T S$

C

$126 Q R=Q R+(Q D R+Q D R L) * D E L T / 2.0$

$Q C=Q C+(Q D C+Q D C L) * D E L T / 2.0$

$Q F M=Q F M+(Q D F M+Q D F M L) * D E L T / 2.0$

$\mathrm{RECS}=\mathrm{RECS}+12.0 *$ (DIFMD $+\mathrm{DIFMDL}) * \mathrm{DELT} / 2.0 / \mathrm{RHOG}$

TLAST $=T$

$Q D F M L=Q D F M$

$Q D C L=Q D C$

$Q D R L=Q D R$

DIFMDL = DIFMD

THETAX = THETA (5)

PHIX $=$ PHI (5)

IF (IPOUT.EQ。1) CALL CLTPT

IF (MACH.LT。SHYCH) ISHH $=1$

IF (MACH.LT.1.0) RLD=RLD2

IF (MACH。LT。1.0) RYD=RYD2

405

406

407

408

409

410

411

412

413

414

415

416

417

418

419

420

421

422

423

424

425

426

IF (H (5).LT.SWALT) ISWH=1

427

428

IF (NHCHEK。EQ.2) GO TO 325

$\operatorname{VB}(1)=V R(I)$

$\operatorname{VTH}(1)=V T H(I)$

$\mathrm{VPH}(1)=\mathrm{VPH}(\mathrm{I})$

$\mathrm{H}(1)=\mathrm{H}(\mathrm{I})$

THETA $(1)=$ THET A $(I)$

$\operatorname{PHI}(1)=\operatorname{PHI}(I)$

$\operatorname{VRD}(1)=\operatorname{VRD}(I)$

$\operatorname{VTHD}(1)=\operatorname{VTHD}(I)$

VPHD (1) $=$ VPHD (I)

CONTINUE INTEGRATICN LOOP

429

430

431

432

433

434

435

436

437

438

$\operatorname{HREX}(1)=\mathrm{HREX}(I)$

439

$I=1$

GO TO 260

c

RECS = RECSL

QDFM $=$ QDFMLS

444

445

$Q D C=Q D C L S$

446

QDR = QDRLS

447

GO TO 136

448

325 IF (IOUT.EQ.0) GO TO 611 
CALI KEPLR

IF (IPASS。GE.NPASS) GO TO 611

136 IOUT $=0$

$I=5$

NHCHEK $=1$

$\mathrm{HCO}=\mathrm{HCOX}$

LNKT $1=50$

KOUT $=$ NOUT

GO TO 240

452

453

454

455

456

457

458

459

IF (NKASE。LE。LKASE) GO TO 10

STOP

C

41 FCRMAT (F10。6,F14.2)

46 FORMAT $(1 \mathrm{X}, 2 \mathrm{I10})$

47 FORMAT (16F8.3)

56 FORMAT $(1 X, 15 F 8.0)$

58 FORMAT $(1 \mathrm{X}, 15 \mathrm{~F} 8.4)$

120 FORMAT $\left(/ 30 X_{0} 11\right.$ HWEIGHT LOSS, $\left./\right)$

125 FORMAT ( $\left.30 \mathrm{X}_{0} 8 \mathrm{HALTITUDE}\right)$

130 FOBMAT (30X, 13HWT-MULTIPLIER)

425 FORMAT (20A4)

435 FORMAT (2I3)

440 FORMAT (6G 12.8$)$

450 FOBMAT (1H $1.17 \mathrm{~A} 4,1 \mathrm{X}, \mathrm{I} 2,1 \mathrm{H} / . \mathrm{I} 2,3 \mathrm{H} / 19 . \mathrm{T} 2)$

475 FORMAT $(12 \times, 16$ HINPUT VARTABLES $/ /$ )

476 FORMAT ( $5 X, 13$ HSTART OF SKIP I I5)

485 FORMAT $(22 \mathrm{X}, 23 \mathrm{H} * * *$ OPTION TABLES ****,/)

486 FORMAT $\left(15 x_{0}\right.$ 24H 1962 STANDARD ATMOSPHERE)

487 FORMAT $(15 X, 24 \mathrm{HCIRCULAR}$ VELOCITY $(F P S)=, F 12.2)$

400 FORMAT $\left(1 X_{0} 6 \mathrm{~F} 13.4\right)$

491 FORMAT ( 8X,2OHLOW MACH NO. TABLE)

$1 \quad 17 \mathrm{H}$ SWITCH WHEN <.F6.2.21日 OR WHEN ALTITUDE< 。

$2 \mathrm{~F} 8.1,5 \mathrm{X}_{*} 2 \mathrm{HCD}, 8 \mathrm{X}, 5 \mathrm{HMACH}$ )

492 FORMAT ( $2 X$, 18 HINITIAL CONDITIONS $/ 25 X$, 8HREIATIVE,6X,8HINERTIAL

$16 X, 17$ HVELOCITY (FPS)

$26 X_{0} 17$ HFLIGHT PATH (DEG)

$36 \mathrm{X}, 17 \mathrm{HAZIMUTH}$ (DEG)

$46 \mathrm{X}, 17 \mathrm{HTIME}$ (SEC)

$56 \mathrm{X}, 17 \mathrm{HWEIGHT}$ (LBS)

$66 \mathrm{X}, 17$ HALT ITUDE (FT)

$76 \mathrm{X}$, 17HLATI TUDE (DEG)

$86 \mathrm{X}, 17$ HLONGITUDE (DEG)

$96 X_{0}, 17$ HREF ABEA (FT*2)

$16 X, 17 \mathrm{HREF}$ IENGTH (ET)

$26 \mathrm{X}, 17 \mathrm{HL} / \mathrm{D}$ SUPEQSONIC

$36 X, 17$ AL $/ D$ SUBSONIC

$46 \mathrm{X}, 17 \mathrm{HY} / \mathrm{D}$ SUPERSONTC

$56 \mathrm{X}, 17 \mathrm{~B} Y / D$ SUBSONIC

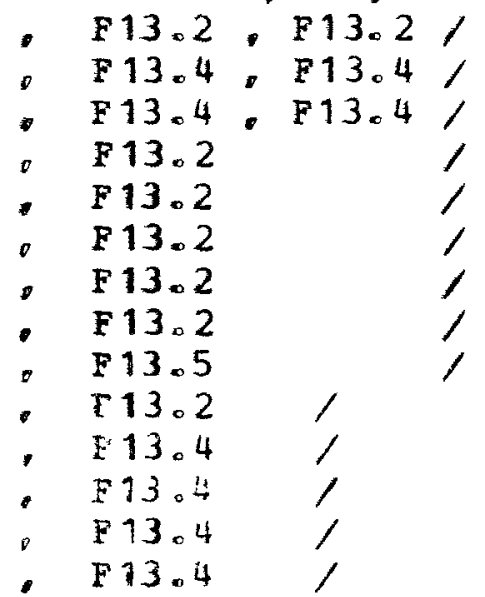

460

461

462

463

464

465

466

467

468

469

470

471

472

473

474

475

476

477

478

479

480

481

482

483

484

485

486

487

488

489

490

491

492

493

494

495

496

407

498

490 
6 6X,17HQ STAG。FACTOR . F13.4 /

$76 \mathrm{X}, 17 \mathrm{HGRAP}$. DENS (PCF) F13.4, )

493 FORMAT (15X, 49 HOBLATE EARTH MODEL, POLAR \& EQUATORIAL RADII (FT) = . 502

$1 / 30 \mathrm{X}, 2 \mathrm{E} 15.8)$

494 FORMAT (15X,31HSPHERICAL EARTH MODEL, RE(FT) =, E15.8)

495 FORMAT $(1 \mathrm{X}, 6 \mathrm{~F} 13.0)$

496 FORMAT (15X, 16 HSTATIONARY EARTH )

497 FORMAT (15X, 11HPRINT EVERY, I4, 11H TIME STEP)

$1 \quad 15 \mathrm{X}, 15 \mathrm{HMAX}$ TIME STEP $=$ F8.4.17 H MIN TIME STEP =.F8.4/

$215 \mathrm{X}, 17 \mathrm{HCUTOFF}$ ALT (FT) $=, \mathrm{F} 8.1,4 \mathrm{H}$ OR, F10.1,

498 FORMAT $(7 X, 35$ HCONSTANTS IN DRAG BRIDGING EQUATION /

$112 \mathrm{X}, 14 \mathrm{HCD}(\mathrm{CONTINUM})=. \mathrm{F} 10.4 .10 \mathrm{H} \quad \mathrm{ED}=. \mathrm{F} 10.5 \%$

$212 \times, 14 \mathrm{HCD}(\mathrm{FBEE} M \mathrm{MOL})=\mathrm{F} 10.4,10 \mathrm{H}$ RNOSE $=, F 10.5)$

499 FORMAT (15X,31HROTATING EARTH,WE(RAD/SEC) =, E15.8)

127 FORMAT (15X, 32 HRADIATIVE FLUX-MODIFIED CALLIS) END

C

SUBROUTINE CALC

C

C

SUBROUT INE CALC

COMMON/DPRES/RE, H (5), AZR,GAMR, WE, T, GR, AD, AL, AY

COMMON/FLOT/THETO. PHIO, THETAX,PHIX,GO, MASS, RAD, RHO,WTMULT,

1 TOLD, VAIR, MACH, QBAR, REY,CD,CA,HJACK, VSOUND, TEMP, WO, SREF,

2 TFIL, WFIL, CAFIL,SKINFR,DWT, QC, QR, QDC, QDR, AZO, TO,

3 PRS,MOL , CASE (17), QDFM, QFM, CDC, CDFM, RNOSE, ED, HOUT, GAMI, VI,

4 AZI,XLAT,XLONG, DIFMD RANGE, RANGEO, HTS, RLD, RECS, DREF, RYD COMMON/FIXED/I, NWT, NALT, NVEL, JACK, NMACH, LNKT 1, KCUT, NHCHEK,

1 NOUT, KJACK, IAERO, NCD, NMAC, ISWH, IOUT, IPASS, NPASS, I RUNCH, JDATE(3)

COMMON/TBLS/ DLWT(100),WALT(100),CATBL (100), ALTTBL (25),

1 CASFTB $(25,10)$,TBLMAC (100),VELTBL (10), CDTBL (100), ALTBL (100) ,

2 CDMTBL (100), TBLMA (100)

DOUBLE PEECISION $R E, H, A Z R, G A M R, H E, T, G R, A D, A L, A Y$

REAL MACH, MASS, MRAT, MOLW

MACH $=$ VAIR/VSOOND

$\mathrm{HHHH}=\mathrm{H}(\mathrm{I})$

$\mathrm{C}$

IF (IAERO.LT.O) GO TO 91

AERO TABLES CA

503

504

505

506

507

508

509

510

511

512

573

514

515

516

517

518

519

520

521

522

523

524

525

526

527

528

529

530

531

532

533

534

535

536

IF (IAERO.EQ.0) GO TO 92

537

$C A=\operatorname{PIE} 1$ (MACH,TBLMAC,NMACH,CATBL)

538

GO TO 90

539

540

91 IF (ISWH.EQ。1) GO TO 93

$$
\text { DRAG COEFFICEINT = F (ALT) }
$$

541

$C A=P I F 1$ (HHHH,ALTBL,NCD,CDTBL)

GO TO 90

C

DRAG COEFFICIENT WITH BRIDGING

542

543

544

545

546

$\mathrm{B}=(\mathrm{CDFM}-\mathrm{CDC}) / \mathrm{CDC}$

$C=(7.32 E+6) *$ RNOSE*RHO *GO*(1.0 $+E D)$

547

$C A=C D C$

$\operatorname{IF}(\mathrm{C} . \mathrm{LT} .50) \quad \mathrm{CA}=\operatorname{CDC} *\left(1.0+\mathrm{B}^{*} \operatorname{EXP}(-\mathrm{C})\right)$

548

$54 \%$ 
GO TO 90

550

$93 \mathrm{CA}=\operatorname{PIF} 1(\mathrm{MACH}, \mathrm{TBLMA}, \mathrm{NMAC}, \mathrm{CDMTBL})$

551

C

WEIGHT LOSS

552

553

$\mathrm{C}$

90 IF (DWT.EQ.0.0) GO TO 110

WTMULT $=$ PIF 1 (HBHH, NALT, NGT,DLHT)

554

MASS $=$ WO/GO WTMULT

C

$\mathrm{C}$

WEIGHT, CA CHANGE VS. TIME

555

556

557

558

C

110 IF (TFIL.LE。O.0) GO TO 135

IF (T.GE.TFIL) GO To 125

MASS $=($ FIL $/ G O) *$ WTHILT

$C A=C A * C A F T L$

GL $=0132$

$125 \mathbb{R L S S}=(15 / 3 C) *$ TQULI

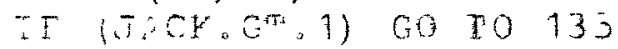

HUACK $=C U I D+((I F I L-T C L L) /(T-T O L D)) *\left(B(5)-C C_{L} L\right)$

$\operatorname{JSCR}=2$

GO TO $1: 5$

$130 \operatorname{COLD}=\mathrm{H}(1)$

$\operatorname{TOL} D=T$

C

$1: 5$ CONTINUE

SKIN FEICTION

559

560

562

563

564

565

$56 \%$

37

$-\therefore$

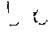

द

57 ;

$57:$

57.

575

576

IF (SKINFR) $140,205,140$

140 DO $143 \therefore=1$, NALI

IF (ALTTBL (J)。GT。HHHH) GO TO 150

577

578

579

145 CONTINUE

$\mathfrak{J}=$ NAL $T$

150 DO $155 \mathrm{~K}=1$, NVEL

IF (VELTBL (K).GT.VAIR) GO TO 160

580

581

582

583

584

585

$\mathrm{K}=\mathrm{NVEL}$

$160 \operatorname{ALTRAT}=($ HHAH-ALTTBL $(J-1)) /(\operatorname{ALTTBL}(\mathrm{J})-\operatorname{ALTTBL}(\mathrm{J}-1))$

586

587

$E=\operatorname{CASTTB}(J-1, K-1)+\operatorname{ALTRAT} *(\operatorname{CASFTB}(J, K-1)-\operatorname{CASFTB}(J-1, K-1))$

$F=\operatorname{CASFTB}(J-1, K)+\operatorname{ALTRAT*}(\operatorname{CASFTB}(J, K)-\operatorname{CASFTB}(J-1, K))$

$C A S F=E+\nabla R A T *(F-E)$

$C A=C A+C A S F$

C

205 QBAR=0.5*RHO*VAIR* 2

PARAMETER CALCULATIONS

588

589

590

591

592

593

594

595

$A X=C A * A / G O$

596

$C D=C A$

597

$C L=C D * R L D$

598

$A D=C D * A$

599 
$A Y=B Y D * A D$

600

RETURN

END

601

602

C

603

SUBROUTINE OUTPT

COMYON/DPRES/RE, H(5),AZR,GAMR, WE, T, GR, AD, AL, AY

COMMON/FLOT /THETO, EHIO, THETAX, PHIX, GO, MASS, RAD, RHO, WTMULT,

604

605

1 TOLD, VAIR, MACH, QBAR, BEY, CD,CA, HJACK, VSOUND, TEMP, WO, SREF,

2 TFIL, WFIL,CAFIL, SKINFR, DWT, QC, QR, QDC, QDR, AZO, TO,

3 PBS, MOLW, CASE (17), QDFM, QFM, CDC, CDEM, RNOSE, ED, HOUT, GAMI, VI,

4 AZT,XLAT, XLONG, DIFMD „RANGE, RANGEO, HTS, RLD, RECS, DEEF, RYD

COMMON/FIXED/I, NWT, NALT, NVEL, JACK, NMACH, LNKT1, KOUT, NHCHEK,

1 NOUT, KJACK, IAERO, NCD, NMAC, ISWH, IOUT, IPASS, NPASS, IPUNCH, JDATE (3)

DOUBLE PRECISION RE,H, AZR, GAMR, WE, T, GR, AD, AL, AY

c

REAL MACH, MASS, MRAT, MOLW, LAT, LON

IF (NHCHEK.EQ.2) GO TO 335

LIST OUTPUT

IF (KOUT.LT.NOUT) GO TO 330

GO TO 335

$330 \mathrm{KOUT}=\mathrm{KOUT}+1$

GO TO 370

335 IF (LNKT1.LE.35) GO TO 345

WRITE $(6.451)$

WRITE $(6,450)$ CASE, JDATE

WRITE $(6.455)$

$I N R^{3}=0$

345 IE(TEIL.IE.0.0) GO TO 365

IF (KJACK。GI。1) GO TO 365

IF (T.IT.TFIL) GO TO 365

606

607

608

609

610

611

612

613

614

615

616

617

618

619

620

621

622

623

624

625

$52 \mathrm{~h}$

627

VRITE $(6,360)$ TEIL, H JACK

628

629

KJ ACK $=2$

365 LAT $=90.0$ - THETAX *RAD

630

631

LON $=$ PHIX *RAD-WE* $(T-T O) * R A D$

632

GAMMA $=$ GAMR*RAD

633

$A Z=A Z R * R A D$

$\mathrm{DR}=(\mathrm{THETAX} \quad-\mathrm{THETO}) * \mathrm{RE}$

$C R=(P H I X \quad-P H I O) * R E *$ SIN (THETO)

DRANGE $=-D R * \operatorname{COS}(A Z O / R A D)+C R * S I N(A Z O / R A D)$

CRANGE $=D R * S I N(A Z O / R A D)+C R * \operatorname{COS}(A Z O / R A D)$

634

635

636

637

RANGE $=$ SQRT (DRANGE* *2 CRANGE*2)/6080.0+RANGEO

638

VIS $=9.898 E-7 *($ TEMP/1.8)* *1.5/(110.4+TEMP/1.8)

REY = BHO*VAIR*DREF*GO/VIS

$X K N U=M A C H / S Q R T$ (REY)

WT $=$ WO*WTMUIT

$B E T A=W T /(C D * S R E F)$

$\mathrm{REY}=\mathrm{REY} / 1.0 \mathrm{E}+6$

$\mathrm{GSEC}=\mathrm{AD} / \mathrm{GO}$

639

640

641

642

643

644

645

646

C TOTAL PRESSURE

647

IF (MACH.LT.5.0) GO TO 301

C HYPERSONIC FLOW

648

649 


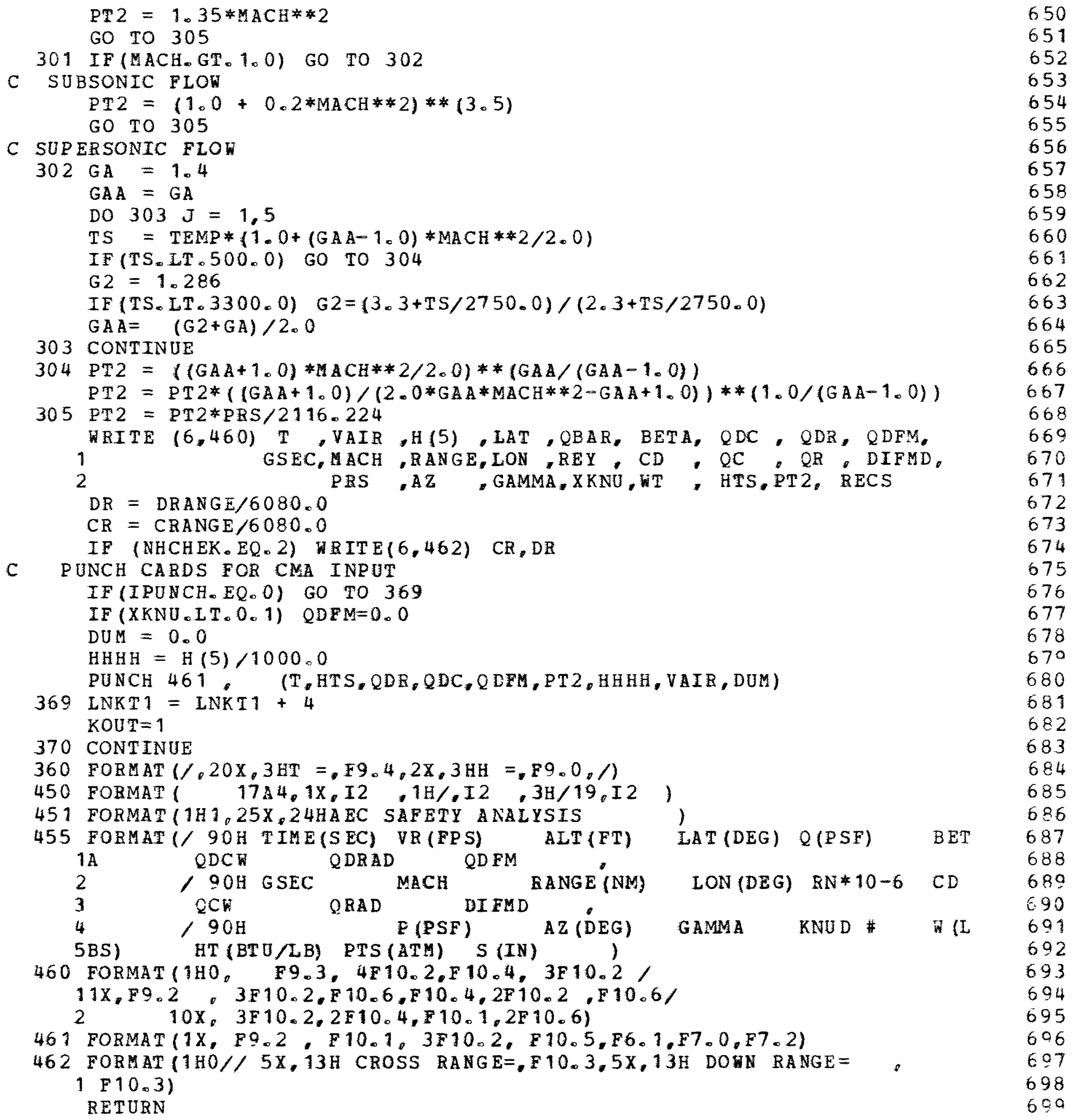


END

SUBROUTINE KEPLR

COMMON/DPRES/RE, H (5),AZR, GAMR, WE,T, GR, AD, AL, AY

COMMON/FLOT /THETO, PHIO, THETAX,PHIX, GO, MASS, RAD, RHO, WTMULT,

1 TOLD,VAIR, MACH, QBAR, REY,CD,CA, HJACK, VSCUND, TEMP, NO, SREF,

2 TFIL, WFIL, CAFIL, SKINFR, DWT, QC,QR, QDC, QDR,AZO, TO,

3 PRS, MOL , CASE (17), QDFM, QFM, CDC, CDFM, RNOSE, ED, HOUT, GAMI, VI,

4 AZI, XLAT, XLONG, DIFMD RANGE, RANGEO, HTS,RLD, RECS, DREF, RYD

702

703

704

705

706

707

708

709 COMMON/FIXED/I, NWT, NALT, NVEL, JACK, NMACH, LNKT 1, KOUT, NHCHEK,

1 NOUT, KJACK, IAERO, NCE, NMAC, IS KH, IOUT, IPASS, NPASS, I PUNCH, JDATE (3)

DOUBLE PRECISION RE,H, AZR, GAMR,WE, T, GR, AD, AL, AY

REAL MACH, MASS, MRAT, MOLY

IPASS = IPASS +1

GAMJ = GAMR

$\mathrm{AZJ}=\mathrm{AZR}$

$X L O=$ PHIX $-W E *(T-T O)$

$H I=H(I)$

$X L=1.5707963-$ THETAX

C CONVERT TO INEBTIAL VALUES

$H R E=R E+H I$

$C 1=H R E *$ WE*COS $(X L) / V A I R$

VI $=$ VAIR*SQRT $(1.0+C 1 * 2 * 2.0 * \operatorname{COS}(G A M J) * \operatorname{SIN}(A Z J) * C 1)$

GAMI $=\operatorname{ARSIN}(V A I R * S I N(G A M J) / V I)$

$A Z I=A T A N 2(S I N(A Z J) * \operatorname{COS}(G A M J)+C 1, \operatorname{COS}(G A M J) * \operatorname{COS}(A Z J))$

710

711

712

713

714

715

716

717

718

719

720

721

722

723

724

725

726

727

728

729

730

731

732

733

734

735

736

737

738

739

740

741

742

743

744

745

746

747

748

749 


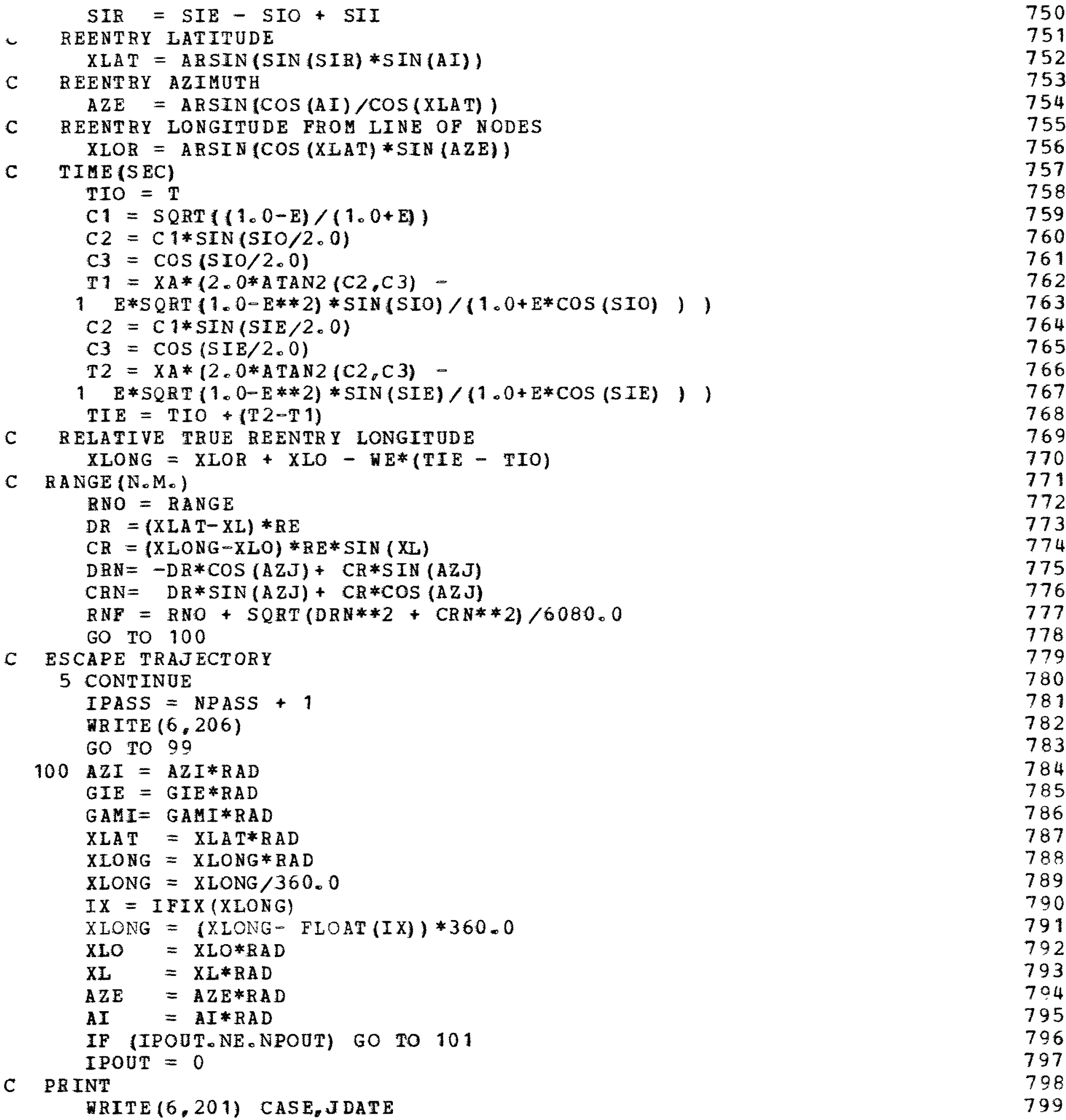


IF (VR.GT.1.0) GO TO 10

800

WRITE $(6,203)$ IPASS

801

GO TO 11

10 TRITE $(6,202)$ IPASS

11 CONTINUE

WRITE $(6,204) \quad E, R P, B A, T M, A I$

WRITE $(6,205) \mathrm{HI}, \mathrm{HE}, \mathrm{VI}, \mathrm{VIE}, \mathrm{GAMI}, \mathrm{GIE}$, AZI, AZE,

1XL, XLAT, XLO, XLONG, TIO, TIE, RNO, RNE

101 IPOUT $=$ IPOUT +1

$I R I=0$

RANGEO $=0.0$

$V I=V I E$

$\mathrm{AZI}=\mathrm{AZE}$

GAMI $=$ GIE

TO $=0.0$

$V I=V I E$

$H I=H E$

C FORMAT STATEMENTS

201 FORMAT $(1 \mathrm{H} 1,17 \mathrm{~A} 4,1 \mathrm{X}, \mathrm{I} 2,1 \mathrm{H} /, \mathrm{I} 2,3 \mathrm{H} / 19, \mathrm{I} 2)$

202 FORMAT $(23 \mathrm{X}, 17$ HMULTICRBIT. PASS, I3)

203 FORMAT $(23 \mathrm{X}$ 。10HSKIP. PASS, I2)

204 FORMAT $(4 X, 16$ HORBIT PARAMETERS

$18 X, 20$ H ECCENTRICITY

$28 X, 20$ HPERIGEE (MILES)

- F 10.4

- F 10.2\%

$38 X, 20 H A P P O G E E$ (NILES)

- $10.2 \%$

$48 X, 20 \mathrm{HPERIOD}$ (HR)

- F10.2/

$58 \mathrm{X}, 20$ HORBIT INCLIN。(DEG), F10.2)

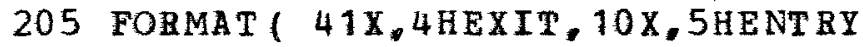

$18 \mathrm{X}, 25 \mathrm{HGEOCENTRIC} \mathrm{ALT} \mathrm{(FT)}$

$28 X, 25 H$ VELOCITY (FPS)

$38 X, 25 H F L I G H T$ PATH ANG (DEG)

$48 \mathrm{X}, 25 \mathrm{HAZIMUTH}$ (DEG)

$58 X, 25 H L A T I T U D E-G E O C E N T R I C$ (DEG)

$68 X, 25 H$ LONGITUDE (DEG)

$78 X 。 25 H T I M E$ (SEC)

$88 \mathrm{X}, 25 \mathrm{HRANGE}(\mathrm{N}, \mathrm{M})$

- F12.1.4X.F12.1/

- F12.1,4X,F12.1/

- F12.3,4X,F12.3\%

- F12.3.4X,F12.3\%

802

803

804

805

806

807

808

809

810

811

812

813

814

815

816

817

818

819

820

821

822

823

824

825

826

827

828

829

830

831

832

- F12.3,4X,F12.3/

833

834

- F12.2.4X,F12.2/

835

206 FORMAT (4X, 46HCONFIGURATION IS ON ESCAPE ORBIT - ALL IS WELL)

99 RETURN END

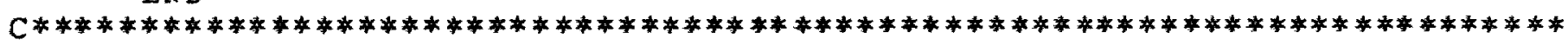

837

838

839

840

FUNCTION AZMUTH (YN,XD)

C

C

FUNCTION AZMUTH

841

842

843

$\operatorname{AT}=\operatorname{ABS}(\operatorname{ATAN}(\mathrm{YN} / \mathrm{XD}))$

$A C=A B S(A T A N(X D / Y N))$

IF (ABS (XD) $-L T A B S(Y N))$ GO TO 45

IF (YN) $15,80,30$

15 IF (XD.GT.0.0) GO TO 25

$20 \mathrm{ARCTAN}=-3.14159265+\mathrm{AT}$

844

845

846

847

848

849 


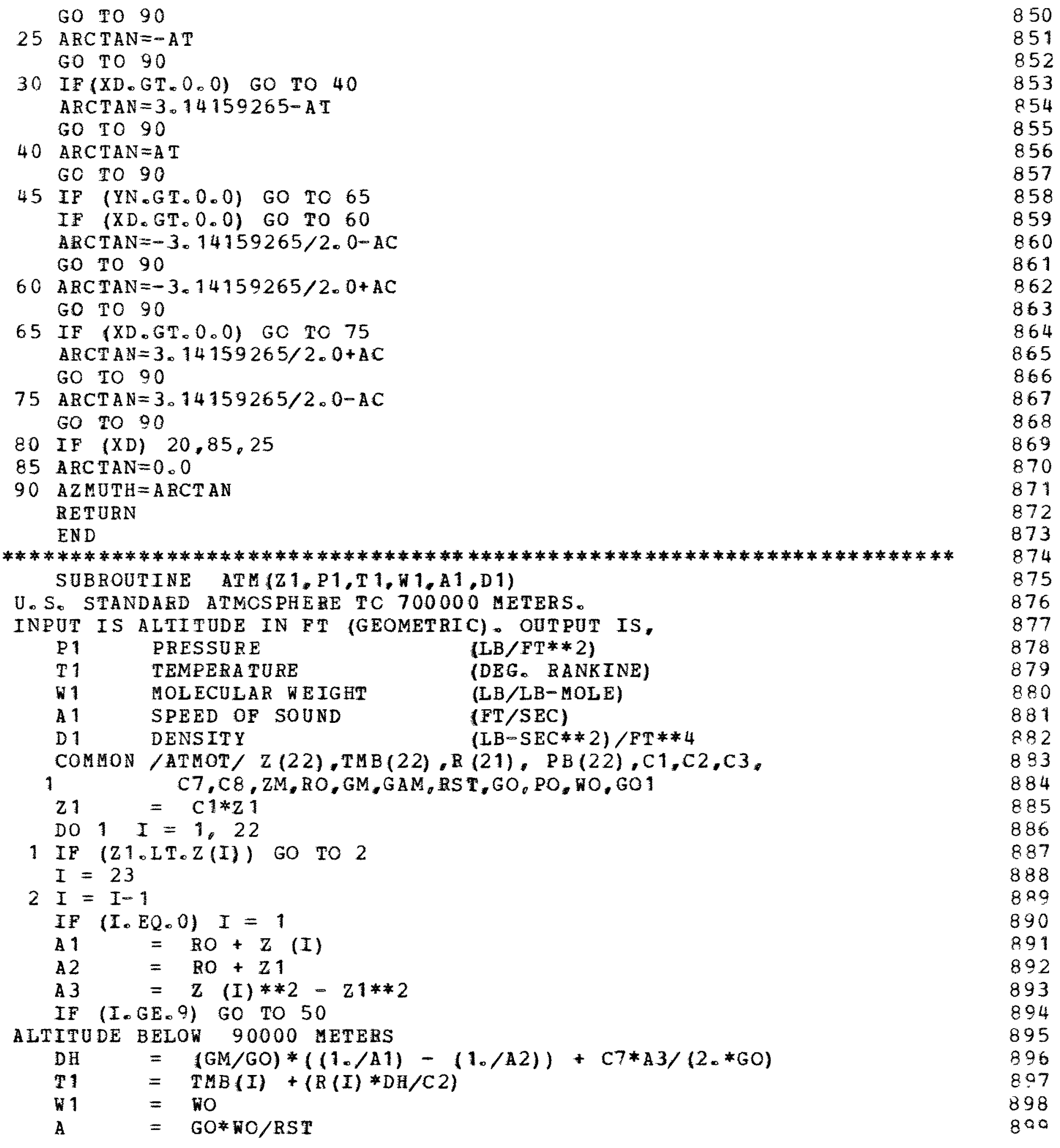


DO $11 \mathrm{~K}=1,3$

$\mathrm{J}=-1+3 * \mathrm{~K}$

11 IF (I.EQ.J) GO TO 12

$\mathrm{P} 1=\mathrm{PB}(\mathrm{I}) *($ (TMB (I) $/(\mathrm{TMB}(\mathrm{I})+(\mathrm{R}(\mathrm{I}) * \mathrm{DH} / \mathrm{C} 2))) *(\mathrm{~A} / \mathrm{R}(\mathrm{I})))$

GO TO 200

$12 \mathrm{P} 1=\mathrm{PB}(\mathrm{I}) * \mathrm{EXP}(-\mathrm{A} * \mathrm{DH} /(\mathrm{TNB}(\mathrm{I}) * \mathrm{C} 2))$

GO TO 200

ALTITUDE ABOVE 90000 METERS

$50 \mathrm{Z1}=\mathrm{Z} 1 / \mathrm{C} 2$

IF (21.GE.110.0) GO TO 51

W1 $=17.98+0.239 * \mathrm{Z} 1-0.0013 *(\mathrm{Z} 1 * 2)$

GO TO 53

51 IF $(Z 1 . G T .170 .0)$ GO TO 57

$W 1=-.41873644 \mathrm{E}+02+.22496378 \mathrm{E}+01 * \mathrm{Z} 1-.25825938 \mathrm{E}-01 *(\mathrm{Z} 1 * 2)$

$1+.12705198 \mathrm{E}-03 *(\mathrm{Z} 1 * 3)-.22989608 \mathrm{E}-06 *(\mathrm{Z}) * 4)$

GO TO 53

$57 W 1=+.28312068 \mathrm{E}+02+.11190901 \mathrm{E}-01 * \mathrm{Z1}=.18061034 \mathrm{E}-03 *(\mathrm{Z} 1 * 2)$

$1+.31829429 E-06 *(Z 1 * * 3)-.16924926 E-09 *(Z 1 * * 4)$

$53 \mathrm{Z1}=\mathrm{Z1} * \mathrm{C} 2$

$\mathrm{TM}=\mathrm{THB}(\mathrm{I})+(\mathrm{R}(\mathrm{I}) *(\mathrm{Z} 1-\mathrm{Z}(\mathrm{I})) / \mathrm{C} 2)$

T1 $1=($ W1/WO $) * T M$

A $=-\mathrm{Z}(\mathrm{I})+(\mathrm{TMB}(\mathrm{I}) * \mathrm{C} 2 / \mathrm{R}(\mathrm{I}))$

A $5=$ WO*C $2 /$ (B (I) *RST)

$A 6=\mathrm{Z}(\mathrm{I})+\mathrm{A} 4$

A $7=\mathrm{Z1}+\mathrm{A} 4$

$A 8=\mathrm{EO}-\mathrm{A} 4$

$A 9=($ (Z (I) $-\mathrm{Z} 1) /(\mathrm{A} 1 * \mathrm{~A} 2))+(1 . / \mathrm{A} 8) * \operatorname{ALOG}(\mathrm{A} 7 * \mathrm{~A} 1 /(\mathrm{A} 6 * \mathrm{~A} 2))$

$A 10=(Z(I)-Z 1)+A 4 * A L C G(A 7 / A 6)$

A $11=(-(G M / A B) * A 9-C 7 * A 10) *$ Ho/(R (I)*RST)

$\mathrm{P} 1=\mathrm{PB}(\mathrm{I}) * \operatorname{EXP}(\mathrm{A} 11)$

PRESSURE, TEMPERATURE AND MOLECULAR WEIGHT FOUND.

$200 \mathrm{P1}=\mathrm{PO} * \mathrm{P} 1$

$Z_{1} 1=21 / \mathrm{C} 1$

$T 1=T 1 * C 3$

$\mathrm{A} 2=\mathrm{RST} * 185.86126 / \mathrm{W} 1$

A $1=\mathrm{SQRT} \quad(\mathrm{GAM} * \mathrm{~A} 2 * \mathrm{~T}) * \mathrm{GO} * \mathrm{C} 8)$

$D 1=P 1 /(A 2 * T 1 * G 01)$

RETURN

END

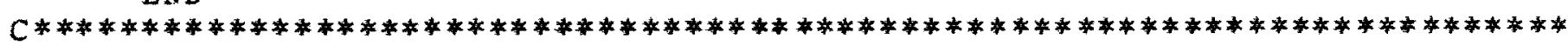

FUNCTION PIF1 (X,XLIST,N,FIIST)

NEW PIF 1

CPIF1 LINEAR INTERPOLATION IN ONE VARIABLE CORRECTED 6-8-66 TTR

DIMENSION XLIST (1)。FLIST (1)

DO $6 I=2, \mathrm{~N}$

$\operatorname{IF}(X-X \operatorname{LIST}(I)) 7,7,6$

6 CONTINUE

$I=\mathrm{N}$

$70 P I F 1=\operatorname{FLIST}(I-1)+(X-X \operatorname{XIST}(I-1)) *(\operatorname{FLIST}(I)-\operatorname{PLIST}(I-1)) /$

000

901

902

903

904

905

906

907

008

909

910

911

912

913

914

915

916

917

918

919

Q 20

921

922

923

924

a 25

926

927

028

929

930

931

932

933

934

935

936

○ 37

938

930

040

941

942

943

044

945

946

947

948

949 
71 (XLIST (I)-XLIST $(I-1)$ )

950

RETURN

951

END

952

$-A 20-$ 
A PPENDIX II

LISTING OF INPUT DECK

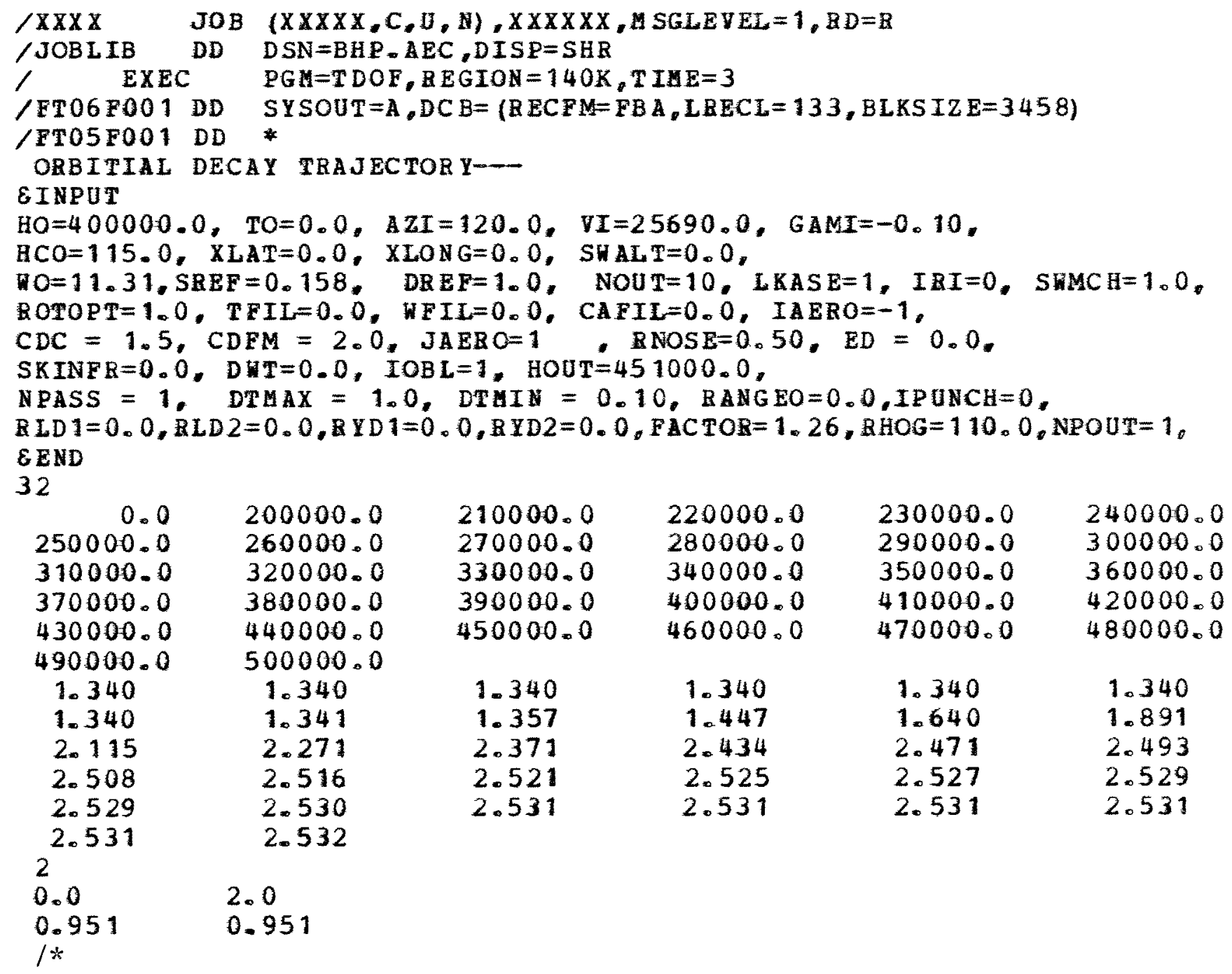

